A puntes del CEN ES

ISSN 0120-3053

Volumen 30 - №. 52

Segundo Semestre 2011

Págs. 145 - 181

\title{
Caracterización de la gestión de la innovación en las empresas del sector manufacturero de Boyacá
}

\section{Characterization of the innovation management in manufacturing sector enterprises of Boyacá}

\author{
José Luis Cruz Vásquez* \\ Diana M aría Dueñas Quintero** \\ Erika Brigith Rojas Del Basto***
}

Fecha de recepción: 28 de marzo de 2011

F echa de aprobación: 27 mayo de 2011

Economista, magíster en Economía, docente de la Escuela de Economía de la Universidad Pedagógica y Tecnológica de Colombia - UPTC. Correo electrónico: jlcruzv@gmail.com

** Administradora de empresas, candidata a magíster en Administración de Empresas, Co-investigadora Centro Regional de Gestión para la Productividad y la Innovación de Boyacá - CREPIB. Correo electrónico: dianamarad780@gmail.com

*** Economista, joven investigadora del grupo interdisciplinar: Equipo CREPIB de la Universidad Pedagógica y Tecnológica de Colombia - UPTC. Correo electrónico: brikika7@gmail.com 


\section{Resumen}

La empresa contemporánea se enfrenta a nuevos retos, de ahí que la innovación tome un papel preponderante en el éxito de la empresa frente a su competencia, brindándole características difer enciales que se constituyen como ventajas competitivas. En el presente artículo se presentan los resultados del proceso de investigación sobre la incidencia de las políticas de ciencia, tecnología e innovación, en la generación de capacidades de gestión de innovación en las empresas del sector manufacturero del departamento de Boyacá.

Palabras clave: políticas de ciencia y tecnología, capacidades de innovación, ventajas competitivas.

Clasificación JEL: L6, 032, 038.

\section{Abstract}

The contemporary company faces new challenges; hence innovation takes a leading role in the success of the company against its competitors, providing differ ent features that are as competitive advantages. In this article we present the results of the research on the impact of science, technology and innovation policies, in building capacity in management of innovation in the manufacturing sector of the department of Boyacá.

Keywords: science and technology policies, innovation capabilities, competitive advantages.

JEL Clasificaction: L6, 032, 038. 


\section{Introducción}

La ciencia, la tecnología, la innovación y el conocimiento son elementos fundamentales del crecimiento económico y social, para alcanzar un desarrollo sostenible que procure aumentar la competitividad y erradicar la pobreza. Por lo tanto es imprescindible, avanzar hacia políticas públicas de carácter integral, que construyan una sociedad basada en el conocimiento y además incorporen instrumentos que proporcionen asesoría, consultoría y acompañamiento a las empresas en materia de gestión de innovación (CEPAL, 2008; UNESCO, 2010).

Partiendo de la necesidad de identificar la existencia de estas políticas en el sector empresarial, el presente artículo presenta los resultados de la investigación denominada Incidencia de las políticas de ciencia, tecnología e innovación (CTI) en la generación de capacidades de gestión de innovación del sector manufacturero del departamento de Boyacá, en alianza del Centro Regional de Gestión para la Productividad y la Innovación de Boyacá (CREPIB), el Grupo de Investigación Observatorio de Análisis y Coyuntura Económica Regional y Urbana (Oikos). Esta investigación hace parte del Plan de Fortalecimiento Institucional Fortalecimiento de la capacidad de gestión del CREPIB en la apropiación de investigación, desarrollo e innovación $(\mathrm{I}+\mathrm{D}+\mathrm{i})$ en los sectores productivos (2010), apoyado por el Departamento Nacional de Ciencia, Tecnología e Innovación COLCIENCIAS.

Este documento se divide en tres secciones: la primera describe el contexto de las políticas de ciencia, tecnología e innovación (CTI) a nivel nacional y regional; en la segunda sección se 
presenta un breve análisis conceptual de las capacidades de gestión de innovación, y por último exponen los resultados de la investigación en las empresas del sector manufacturero del departamento de Boyacá.

\section{Metodología}

Para esta investigación, se revisaron las fuentes secundarias con el fin de contextualizar las políticas de CTI, las capacidades de gestión de innovación y el contexto empresarial de Boyacá. en la recolección de información primaria se aplicó la encuesta denominada
Apropiación de la gestión del conocimiento, el desarrollo tecnológico y la innovación (CREPIB, 2010) a 112 empresarios del sector manufacturero, seleccionados por el método aleatorio simple. Esta encuesta contiene ocho variables establecidas de acuerdo con referentes bibliográficos (Tabla 1), tomando como referencia especialmente la encuesta de desarrollo e innovación tecnológica EDIT I, II y III (DANE s.f.). El tratamiento de la información suministrada se efectuó a partir del análisis descriptivo relacionando los resultados de las empresas con las políticas de CTI existentes en el departamento de Boyacá.

Tabla 1. Definición de variables

\begin{tabular}{|c|c|}
\hline Variables & Referencias \\
\hline $\begin{array}{l}\text { Capacidad de } \\
\text { vinculación }\end{array}$ & $\begin{array}{l}\text { CREPIB, De Saá (2006), Robledo (2008) Santos (2008) Maldonado, } \\
\text { (2004) Yoguel (2000), CIDEM (2002). }\end{array}$ \\
\hline $\begin{array}{l}\text { Comportamiento } \\
\text { competitivo de la } \\
\text { empresa }\end{array}$ & $\begin{array}{l}\text { Calderón (2007), Robledo (2008), Santos (2008), Maldonado } \\
\text { (2004), Yoguel (2000), CIDEM (2002), Flores (2005). }\end{array}$ \\
\hline Innovación & DANE, COLCIENCIAS, Malaver (2004), Vargas (2004). \\
\hline $\begin{array}{l}\text { Planificación en } \\
\text { innovación y desa- } \\
\text { rrollo tecnológico }\end{array}$ & $\begin{array}{l}\text { ITA, COLCIENCIAS, Malaver (2003), OCDE (2005), De Saá } \\
\text { (2006), CIDEM (2002). }\end{array}$ \\
\hline $\begin{array}{l}\text { Cultura de } \\
\text { innovación }\end{array}$ & COLCIENCIAS, Bravo (2009), CIDEM (2002), Calderon (2007). \\
\hline Talento humano & $\begin{array}{l}\text { DANE, COLCIENCIAS, Malaver (2003), Flores (2005), De Saá } \\
\text { (2006), Bravo (2009), Yoguel (2000). }\end{array}$ \\
\hline $\begin{array}{l}\text { Capacidad } \\
\text { tecnológica }\end{array}$ & DANE, CREPIB, Malaver (2003), López (2006), Robledo (2009). \\
\hline $\begin{array}{l}\text { Gestión del } \\
\text { conocimiento }\end{array}$ & COLCIENCIAS, CREPIB, Senior (2006), Yoguel (2000). \\
\hline
\end{tabular}

Fuente: elaboración de los autores 


\section{Contexto de la política de ciencia,} tecnología e innovación

La política de ciencia, tecnología e innovación busca influir en el sector productivo para fortalecer al sector empresarial, por medio de la creación de ventajas competitivas, de manera que mejoren la productividad y la competitividad (Heijs, 2001). A continuación se presenta la justificación teórica de la intervención del Estado y los lineamientos de la política en materia de CTI que apoyan la generación de capacidades de innovación.

El desarrollo tecnológico en la década del setenta, era concebido bajo el análisis del modelo lineal que comprendía a la innovación como un proceso ordenado y secuencial llevado a cabo en fases aisladas, el cual inicia con trabajos de investigación básica y finaliza con la introducción de innovaciones en el mercado, en tanto que la innovación era de carácter académico y la tecnología se consideraba solamente como información (Velasco, 2007).

En el modelo lineal, las políticas están enfocadas a la generación de innovaciones, por medio de la creación de centros de investigación y la financiación directa de actividades de investigación empresariales, sin tener en cuenta el alcance de estos aportes en el beneficio socioeconómico (Chudnovsky, 1998; Albornoz, 2009).

En oposición al modelo lineal, surgió el modelo interactivo desarrollado en los años ochenta, promoviendo la interacción continua entre los actores y elementos que intervienen en los procesos de innovación, teniendo en cuenta las capacidades tecnológicas y la gestión de la innovación, como factores estratégicos dentro de las empresas (Heijs, 2001). Este modelo implica cambios radicales para la gestión tecnológica de las empresas y el diseño de la política tecnológica por parte de la administración pública.

Desde el enfoque económico, el diseño de las políticas se relaciona con el papel del Estado, el cual ha sido un tema polémico, pues existen diferentes interpretaciones en cuanto a su intervención en asuntos económicos. Para el caso de bienes tecnológicos, se revisan las opiniones de las escuelas neoclásica y evolutiva, en las que existen diversos de puntos de vista. Particularmente para Adam Smith, la intervención del Estado era impertinente e innecesaria. Según su doctrina de la mano invisible, los individuos cuentan con libertad natural (laissez faire) y sabiduría divina, conocen bien sus intereses para tomar decisiones correctas, que no solo traerán beneficios individuales sino a toda la sociedad (Ekelund, 2003).

En oposición a esta teoría, los neoclásicos aseguran que la intervención del Estado en la asignación de los recursos científicos y tecnológicos es pertinente a causa de la presencia de fallos en el mercado, teniendo en cuenta que los bienes tecnológicos no cumplen las condiciones de competencia perfecta, pues influyen en los precios y restringen la entrada al mercado a otros 
productores. Esta situación es consecuencia de la implementación de incentivos a la innovación, tales como: otorgamiento de patentes y derechos exclusivos. (Stiglittz, 2000; González, 2008).

Así pues, los fallos del mercado mencionados por los neoclásicos pueden ser de tres tipos: la incertidumbre, las externalidades y las ventajas de escala. Estos fallos afectan a las empresas disminuyendo sus incentivos de inversión en actividades en I+D, lo cual se ve representado en la Tabla 2, que describe las fallas en el mercado, sus implicaciones y posibles soluciones por parte del Estado.

Tabla 2. Fallos en el mercado para el caso de bienes de la ciencia y la tecnología

\begin{tabular}{|c|c|c|}
\hline Incertidumbre & Ventajas de escala & Externalidades \\
\hline $\begin{array}{l}\text { Desconocimiento de la } \\
\text { probabilidad de cierto } \\
\text { resultado o desenlace. }\end{array}$ & $\begin{array}{l}\text { Riesgos económicos y tecnológicos enfrenta- } \\
\text { dos por la empresa, en la etapa inicial de una } \\
\text { innovación, aunque exista un esfuerzo inno- } \\
\text { vador al principio, los resultados van a ser } \\
\text { mínimos. }\end{array}$ & $\begin{array}{l}\text { Acciones de los } \\
\text { individuos que gene- } \\
\text { ran costes o beneficios } \\
\text { que no se reflejan en } \\
\text { el precio de mercado, } \\
\text { estas pueden ser posi- } \\
\text { tivas o negativas. }\end{array}$ \\
\hline \multicolumn{3}{|c|}{ Implicaciones para el mercado } \\
\hline $\begin{array}{l}\text {-Desigualdades en el } \\
\text { mercado. } \\
\text {-Información asimétrica } \\
\text { e incompleta. }\end{array}$ & -Surgimiento de monopolios. & $\begin{array}{l}\text {-Conocimiento consi- } \\
\text { derado como un bien } \\
\text { público y apropiable. }\end{array}$ \\
\hline \multicolumn{3}{|c|}{ Implicaciones para la empresa } \\
\hline $\begin{array}{l}\text {-Desconocimiento del } \\
\text { tiempo de recupera- } \\
\text { ción de inversiones. } \\
\text {-Dificultad para tomar } \\
\text { dediciones optimas. }\end{array}$ & $\begin{array}{l}\text {-Costes marginales mayores a los beneficios } \\
\text { marginales. } \\
\text {-Pérdidas económicas, en la etapa inicial de } \\
\text { la innovación. }\end{array}$ & $\begin{array}{l}\text {-Disminución de las } \\
\text { rentabilidades espe- } \\
\text { radas. }\end{array}$ \\
\hline \multicolumn{3}{|c|}{$\begin{array}{l}\text { Riesgos elevados de inversión } \\
\text { económica y tecnológica } \\
\text { Disminución de los incentivos } \\
\text { para generar innovaciones }\end{array}$} \\
\hline \multicolumn{3}{|c|}{ Intervención del Estado } \\
\hline $\begin{array}{l}\text { Proporcionar informa- } \\
\text { ción tecnológica, eco- } \\
\text { nómica y de mercados. }\end{array}$ & $\begin{array}{l}\text { Brindar fortalecimiento y acompañamiento } \\
\text { por medio de programas a la estructura de las } \\
\text { empresas, de modo que sean capaces de man- } \\
\text { tenerse hasta la etapa de maduración de la in- } \\
\text { novación. }\end{array}$ & $\begin{array}{l}\text { Incentivar la propie- } \\
\text { dad intelectual. }\end{array}$ \\
\hline
\end{tabular}

Fuente: elaboración propia según los autores Pindyck (2009),Ekelund (2003), Stiglittz (2000), Heijs (2010), Canales (2007), González (2008), Garay (2004). 
Por su lado, la teoría evolucionista afirma que deben existir medidas por parte del Estado que tengan influencia en los procesos de innovación y crecimiento económico, parte del dilema tiene origen en los costes del conocimiento. Respecto al modelo lineal la generación de conocimiento no debe tener costes adicionales de adquisición, mientras el modelo interactivo propone que la imitación de conocimiento sea costosa (Heijs, 2001).

De acuerdo con lo anterior, el modelo interactivo implica que no basta con la generación de nuevo conocimiento, sino que además deben existir políticas de Estado, que estimulen las capacidades tecnológicas e innovadoras del sistema económico, promoviendo procesos de aprendizaje continuo en las empresas. El enfoque evolucionista está centrado en el fomento de la creatividad de las empresas, asimismo debe ser el Estado quien prepare a las empresas para reaccionar ante cambios estructurales y tecnológicos (Heijs, 2001).

En síntesis, se establece que las políticas propuestas por el pensamiento evolutivo pueden ser de dos tipos. El primero, el aprovechamiento de los conocimientos generados en el ámbito interno de las empresas (modelo lineal), y el segundo en el aumento de las capacidades tecnológicas y de conocimiento de las empresas por medio de la transferencia de tecnología (modelo interactivo) (González, 2008).
Respecto a los puntos de vista de los teóricos de las escuelas neoclásica y evolutiva, podemos concluir que en el caso de las innovaciones, la intervención del Estado es necesaria para evitar distorsiones en los mercados, actuando como agente regulador por medio de instrumentos de financiamiento y capacitación (Canales, 2007).

\subsection{Política de ciencia, tecnología e innovación en Colombia}

Colombia inició actividades en ciencia y tecnología de manera informal por medio de colegios y universidades durante la época colonial. Solo hasta el siglo XVIII surgieron organizaciones de carácter científico, dando paso a la formación de maestros, profesores e investigadores por medio de la realización de misiones y expediciones (DNP, 2006). En 1968 se estableció la institucionalidad de la ciencia y tecnología en Colombia, con la creación del Fondo Colombiano de Investigaciones Científicas Francisco José de Caldas COLCIENCIAS, enfocándose en la formación de recurso humano y de grupos de investigación, con el fin de fortalecer las capacidades en ciencia y tecnología. Esta institución fue fundada por los esfuerzos del gobierno nacional y organismos internacionales como la OEA y UNESCO (COLCIENCIAS, 2008).

A partir de la política de CTI definida por medio de Ley 29 de 1990, se han desarrollado alianzas y programas con otras instituciones y universidades, que han 
contribuido a la transferencia y apropiación del conocimiento, en busca del aprovechamiento de los recursos humanos y naturales del país. Durante los últimos tres periodos presidenciales, la intención del gobierno ha sido el fortalecimiento de la institucionalidad de COLCIENCIAS, como departamento administrativo de CTI (la Ley 1286 de 2009), para la generación de competencias científicas y tecnológicas que mejoren los procesos educativos, sociales y productivos (DNP, 1999, 2003, 2007).

\subsubsection{Lineamientos de la política}

En la actualidad, la política de ciencia, tecnología e innovación tiene como objetivo general incrementar la capacidad del país para identificar, producir, difundir, usar e integrar el conocimiento científico y tecnológico, con el propósito de mejorar la competitividad y difundir la transformación productiva del país (DNP, 2009).
En esencia, la política busca estimular tres elementos: la oferta (generación de conocimiento), la demanda (uso) y la interacción entre oferta y demanda, mediante el fortalecimiento institucional del Sistema Nacional de Ciencia, Tecnología e Innovación - SNCTeI, por medio de los objetivos y estrategias presentadas en la Tabla 3 (DNP, 2000).

El Estado, como formulador de la política de CTI en Colombia, ha mostrado interés en apoyar al sistema productivo por medio de la generación y transferencia de conocimiento. En este sentido se resalta la labor del Sistema Nacional de Innovación (SNI) como facilitador de elementos útiles para la formulación de la política, teniendo en cuenta que el SIN es una red de instituciones del sector público y privado, cuyas actividades y acciones inician, importan, modifican y difunden nuevas tecnologías (Abeledo, 2008).

Tabla 3. Objetivos y estrategias de la política de ciencia, tecnología e innovación en Colombia

\begin{tabular}{|l|l|}
\hline \multicolumn{1}{|c|}{ Objetivos } & \multicolumn{1}{c|}{ Estrategias } \\
\hline $\begin{array}{l}\text { 1. Fomentar la } \\
\text { innovación en } \\
\text { los sistemas } \\
\text { productivos. }\end{array}$ & $\begin{array}{l}\text { - Desarrollar y promover un portafolio de incentivos para la innovación. } \\
\text { - Promover la creación y fortalecimiento de unidades de investigación aplicada. } \\
\text { - Formar líderes para la innovación empresarial. }\end{array}$ \\
- Promover la innovación en los sistemas productivos. \\
- Consolidar el sistema de propiedad intelectual. \\
- Implementar lo dispuesto en la Ley 1286 de 2009 y reglamentar el marco normativo \\
de CTeI.
\end{tabular}




\begin{tabular}{|c|c|}
\hline Objetivos & $\begin{array}{c}\text { Estrategias } \\
\end{array}$ \\
\hline $\begin{array}{l}\text { 3. Fortalecer la } \\
\text { formación del } \\
\text { recurso humano } \\
\text { para la investi- } \\
\text { gación y la } \\
\text { innovación. }\end{array}$ & $\begin{array}{l}\text { Fomentar el desarrollo de capacidades de generación y adaptación de conocimiento. } \\
\text { Requiere de un recurso humano capaz de adelantar proyectos de investigación, de } \\
\text { gestionar la innovación al interior de las empresas y adaptar el conocimiento generado } \\
\text { en otros lugares para ser implementado en el país. }\end{array}$ \\
\hline $\begin{array}{l}\text { 4. Promover } \\
\text { la apropiación } \\
\text { social del } \\
\text { conocimiento. }\end{array}$ & $\begin{array}{l}\text { - Promover la divulgación de procesos de investigación e innovación e impactos. } \\
\text { - Generar y difundir nuevo conocimiento. } \\
\text { - Promover alianzas estratégicas en medios masivos de comunicación. } \\
\text { - Definir líneas editoriales en ciencia, tecnología, innovación y sociedad. } \\
\text { - Fomentar la participación ciudadana en los procesos de generación y apropiación } \\
\text { de nuevo conocimiento. } \\
\text { - Crear un sistema de seguimiento y evaluación de la apropiación social. }\end{array}$ \\
\hline $\begin{array}{l}\text { 5. Focalizar la } \\
\text { acción pública } \\
\text { en áreas } \\
\text { estratégicas. }\end{array}$ & $\begin{array}{l}\text { - Implementación de un programa de análisis y estudio permanente de áreas } \\
\text { estratégicas. } \\
\text { - Financiación de proyectos de investigación y programas de formación de alto nivel } \\
\text { específicos. } \\
\text { - Desarrollar proyectos de alta, media y baja complejidad tecnológica. } \\
\text { - Identificar las necesidades de personal e infraestructura del sistema nacional de } \\
\text { calidad, de tal manera que se apoyen las áreas estratégicas. } \\
\text { - Establecer una política de clusters, cadenas de valor, parques tecnológicos u otras } \\
\text { formas de aglomeraciones con la cual se oriente la acción pública alrededor de } \\
\text { iniciativas privadas de innovación. }\end{array}$ \\
\hline $\begin{array}{l}\text { 6. Desarrollar } \\
\text { y fortalecer } \\
\text { capacidades. }\end{array}$ & $\begin{array}{l}\text { - Fortalecer las capacidades regionales para la generación, gestión y uso del } \\
\text { conocimiento. } \\
\text { - Proporcionar capacidades de integración de las regiones con las decisiones de política } \\
\text { que tome el país en CTeI. } \\
\text { - Promover la generación de capacidades territoriales en gestión de la CTeI. } \\
\text { - Apoyar la investigación (generación de conocimiento) en instituciones educativas } \\
\text { de básica, media y superior y centros de investigación y desarrollo tecnológico. } \\
\text { - Consolidar la inserción internacional de la CTeI colombiana. } \\
\text { - Facilitar el acceso de los grupos y centros de investigación y desarrollo tecnológico } \\
\text { del país a recursos. }\end{array}$ \\
\hline
\end{tabular}

Fuente: COLCIENCIAS (2010).

\subsection{Política de ciencia, tecnología e innovación en Boyacá}

El desarrollo de la ciencia y tecnología en el departamento de Boyacá comenzó durante la segunda mitad del siglo XX por medio de la intervención pública, la actividad institucional técnica y de educación superior. Los cambios estructurales a nivel nacional en la década del noventa, dejaron al descubierto la debilidad de la economía boyacense, las empresas del departamento quedaron rezagadas tecnológicamente en comparación con los demás departamentos (Castellanos, 2004). 
Evidentemente estas diferencias interregionales en el desarrollo económico, fueron la consecuencia de la poca efectividad de las políticas nacionales de ciencia, tecnología e innovación. Por tal motivo, en 1980 COLCIENCIAS, desarrolló un proceso de regionalización, con el fin de consolidar bases de planificación regional, permitiendo adaptar las políticas nacionales a las condiciones estructurales de cada región, dando paso a la creación de agendas regionales de CTI y al diseño de programas de ciencia y tecnología en las regiones (Castellanos, 2004; COLCIENCIAS; Pérez, Otero y Campos, 2008).

De este proceso en el año 2000 surge la iniciativa de crear el Centro Regional de Gestión para la Productividad y la Innovación en Boyacá CREPIB, que promueve la apropiación de la ciencia, tecnología e innovación en el sector productivo para fortalecer la productividad y competitividad en el departamento de Boyacá. Asimismo, las universidades departamentales, el Servicio Nacional de Aprendizaje SENA, las cámaras de comercio, la Incubadora de Empresas y el sector empresarial son actores permanentes del sistema regional de CTI. En la Tabla 4 se observan las estrategias de la política nacional y las correspondientes entidades que la ejecutan por medio de programas regionales en el departamento de Boyacá.

El punto de partida para el desarrollo de estas estrategias que contribuyen a la disminución del rezago en los procesos de ciencia y tecnología, fue la articulación de entidades regionales para la construcción de la Agenda Prospectiva Regional de Ciencia y Tecnología (2004). En esta se determinaron líneas estratégicas pertinentes al incremento de ventajas competitivas en el departamento. En este contexto se observan tres ejes importantes en el desarrollo de la ciencia y tecnología de Boyacá: la educación, los entes gubernamentales y el sector productivo (Cely, 2007). 
Tabla 4. Política nacional de ciencia, tecnología e innovación y programas regionales de Boyacá

\begin{tabular}{|c|c|}
\hline $\begin{array}{c}\text { Objetivo de la } \\
\text { Política Nacional }\end{array}$ & Programas Regionales \\
\hline $\begin{array}{l}\text { 1. Fomentar la } \\
\text { innovación en los } \\
\text { sistemas } \\
\text { productivos. }\end{array}$ & $\begin{array}{l}\text { - Fortalecimiento al Centro Regional de Gestión para la Productividad e Innovación } \\
\text { de Boyacá. } \\
\text { - Mejoramiento de la productividad y competitividad a partir del desarrollo tecnológico. } \\
\text { - Creación de incentivos a empresas innovadoras. } \\
\text { - Alianzas para facilitar el otorgamiento de crédito empresarial para innovación y } \\
\text { desarrollo. } \\
\text { - BOYACÁ CRECE INNOVANDO: desarrollar y promover la reconversión } \\
\text { productiva y tecnológica. }\end{array}$ \\
\hline $\begin{array}{l}\text { 2. Consolidar la } \\
\text { institucionalidad } \\
\text { del Sistema } \\
\text { Nacional de } \\
\text { Ciencia, } \\
\text { Tecnología e } \\
\text { Innovación. }\end{array}$ & $\begin{array}{l}\text { - Conformación de un Sistema Regional de Ciencia y Tecnología. } \\
\text { - Gestión de un Sistema Regional de Ciencia, Tecnología e Innovación. } \\
\text { - Fortalecimiento del Capital humano y social en Ciencia, Tecnología e Innovación. } \\
\text { - Desarrollo y Reconversión Productiva y Tecnológica. }\end{array}$ \\
\hline $\begin{array}{l}\text { 3. Fortalecer la } \\
\text { formación del } \\
\text { recurso humano } \\
\text { para la } \\
\text { investigación y } \\
\text { la innovación. }\end{array}$ & $\begin{array}{l}\text { - Destinar recursos y programas para facilitar la formación y el desarrollo del capital } \\
\text { humano vinculado a las MIPYMES. } \\
\text { - Apoyar la formación de alto nivel de profesionales y gestores tecnológicos. } \\
\text { - Creación de un fondo para la gestión de becas en maestría y doctorado para estudios } \\
\text { en el exterior. }\end{array}$ \\
\hline $\begin{array}{l}\text { 4. Promover la } \\
\text { apropiación social } \\
\text { del conocimiento. }\end{array}$ & $\begin{array}{l}\text { - Desarrollo de la Agenda Regional de Ciencia y Tecnología. } \\
\text { - Generación de cultura de ciencia y tecnología en niños y jóvenes. } \\
\text { - Apoyo y fortalecimiento al programa ONDAS y gestión de incentivos a niños y } \\
\text { jóvenes investigadores. }\end{array}$ \\
\hline $\begin{array}{l}5 . \text { Focalizar la } \\
\text { acción pública en } \\
\text { áreas estratégicas. }\end{array}$ & $\begin{array}{l}\text { - Fortalecimiento de la cooperación Universidad - Empresa - CREPIB - Incubadoras. } \\
\text { - BOYACÁ EMPRENDE: formular e implementar una política regional de } \\
\text { emprendimiento, con el fin de incrementar la confianza de los boyacenses para } \\
\text { crear empresa. } \\
\text { - MIPYMES PARA CRECER: desarrollar en los empresarios la formación y las } \\
\text { capacidades gerenciales para un Boyacá competitivo. } \\
\text { - Cofinanciación de proyectos, programas y actividades para el desarrollo tecnológico } \\
\text { de las mipymes y la aplicación de instrumentos no financieros dirigidos a su fomento } \\
\text { y promoción. }\end{array}$ \\
\hline $\begin{array}{l}\text { 6. Desarrollar } \\
\text { y fortalecer } \\
\text { capacidades. }\end{array}$ & $\begin{array}{l}\text { - Transferencia de tecnología. } \\
\text { - Impulso a la conformación de incubadoras de empresas de base tecnológica. } \\
\text { - Creación de un Parque Tecnológico. } \\
\text { - BOYACÁ COMERCIAL: desarrollar e internacionalizar los mercados para } \\
\text { productos y servicios boyacenses. } \\
\text { - Satisfacer las necesidades de legalidad del ejercicio comercial, de información socio- } \\
\text { económica de las empresas. }\end{array}$ \\
\hline
\end{tabular}

Fuente: elaboración propia con base en Asociación de la Industria Navarra (2008), De Saá (2006) Aguilar (2006), Bravo (2009), Senior (2006), CEPAL (2006) y Perozo (2005). 


\section{Capacidades de gestión de innovación}

La innovación es una alternativa estratégica en la competitividad, cuyo propósito es diferenciar los procesos, bienes y servicios de la empresa frente a sus rivales para conseguir éxito, rentabilidad, prosperidad y supervivencia en el mercado. Para alcanzar este propósito las empresas deben generar ventajas competitivas por medio del desarrollo de capacidades de gestión de innovación (De Saá, 2006).

El estudio de las capacidades de gestión de innovación se hace de acuerdo con el enfoque determinado por la teoría económica. Los neoclásicos consideran que las capacidades tecnológicas de una organización o sociedad están en función de las fronteras de sus conocimientos. Para ellos el conocimiento tecnológico se concibe explícitamente, es articulado, imitable, codificable y perfectamente transmisible. La tecnología es creada con anterioridad al proceso productivo (López, 2006).

En oposición, los neoschumpeterianos creen que el conocimiento tecnológico se genera dentro del proceso productivo, en el cual no existen instrucciones precisas, ya que este conocimiento está únicamente en las personas que conocen el proceso; es decir, tiene elementos tácitos que hacen difícil la transferencia e imitación del conocimiento generado (López, 2006).
Sin embargo, para el pensamiento evolucionista, las capacidades reúnen la base del conocimiento de una empresa, adquiridas mediante largos procesos de aprendizaje informal y tácito, puestas en práctica en los procesos productivos (Malaver, 2004). Por su parte, la economía basada en el conocimiento está moldeada por el aprendizaje y motorizada por la innovación, considera que las capacidades colectivas son importantes para la adaptación y cambios de la empresa (López, 2006).

De acuerdo con Flores (2005), las capacidades de innovación refieren a la aplicación de conocimientos nuevos o existentes (o la combinación de los dos tipos de conocimiento) adaptados a las condiciones de la empresa, con el fin de crear capacidades en las empresas para afrontar presiones y riesgos, por medio de estrategias bien formuladas encaminadas a la creación de ventajas competitivas sostenibles.

En consecuencia, las capacidades de innovación definen lo que la empresa debe hacer y cómo debe hacerlo. Teniendo en cuenta que el desarrollo de estas capacidades no es exclusividad del empresario o gerente de la empresa, se considera como un trabajo integral basado en la experiencia y la unión de esfuerzos deliberados, para la solución de problemas y responder a los desafíos competitivos del mercado mediante la interacción con los clientes, las instituciones y otras empresas (Robledo, 2008; Santos, 2008; 
Maldonado, 2004; Yoguel, 2000; Aguilar, 2005; De Saá, 2006).

\subsection{Tipología de las capacidades}

La formación de las capacidades empresariales depende del conjunto de actividades y habilidades para combinar adecuadamente los recursos y generar conocimientos, a partir de procesos de adaptación, cambios e integración de la organización y las rutinas de tipo comportamental que definen lo que las empresas desarrollan para una tarea específica (Aguilar, 2005, 2006; Bravo, 2009; Yoguel, 2000; Malaver, 2004; Flores, 2005) Estas capacidades son importantes para mantener las ventajas competitivas a lo largo del tiempo. Las empresas pueden construir capacidades de innovación, a medida que logren configurar y coordinar aprendizajes para propiciar transformaciones en sus procesos. Estas capacidades pueden clasificarse según el papel que desempeñen dentro de la empresa como se ilustra en el Diagrama 1 (Aguilar, 2005).

La economía presenta cambios continuos, por tanto es necesario que las capacidades sean dinámicas en los ámbitos interno y externo de la empresa, teniendo en cuenta que es importante que además de cumplir las funciones de integrar, construir y reconfigurar puedan orientar rápidamente las estrategias en ambientes que cambian. De acuerdo con la funcionalidad de estas capacidades se puede considerar que para que las empresas tengan estructuras eficaces, es indispensable promover el capital humano y ejecutar acciones colectivas como mecanismo para innovar productos y procesos (Aguilar, 2005; Goméz, 2006; Calderón, 2007).

Diagrama 1. Tipología de las capacidades de acuerdo con las funciones de la empresa.

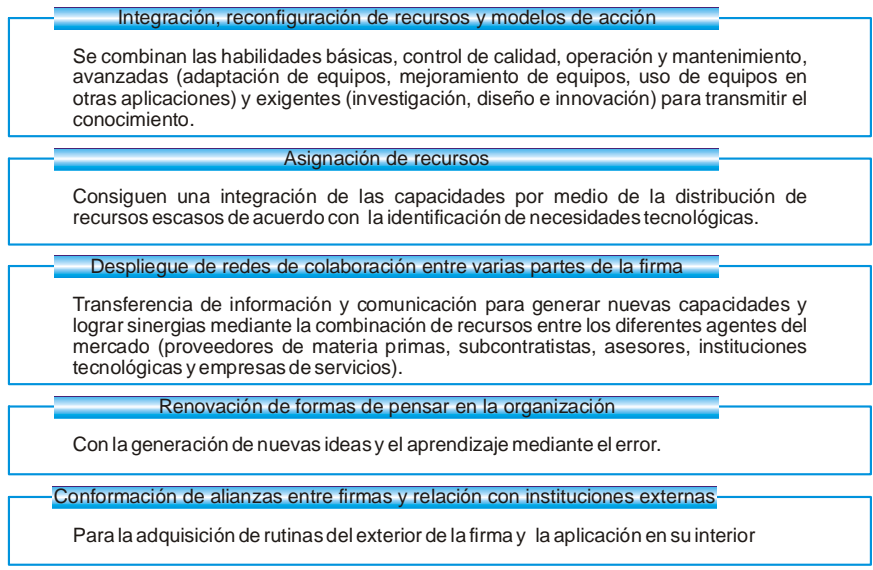

Fuente: elaboración propia de acuerdo con los autores Aguilar (2005) y Flores (2005) 


\subsection{Gestión de la innovación}

La gestión de la innovación comprende un conjunto de técnicas organizativas, para combinar el conocimiento necesario en la satisfacción de necesidades, la identificación de oportunidades tecnológicas y la solución de problemas (Senior, 2006). De esta manera, la gestión permite la interacción eficiente entre tecnología, recurso humano y conocimiento, a fin de obtener aumentos en la calidad, competitividad y productividad de los bienes y servicios ofrecidos (Perozo, 2005).

En la Tabla 5 se presenta la relación existente entre las capacidades generadas dentro de la empresa y la manera como son gestionadas para conseguir que la empresa sea innovadora. No basta solamente con que se incentiven las capacidades, sino que también tengan una dirección adecuada, estableciendo la unión entre las capacidades y la gestión de la innovación.

Tabla 5. Relación capacidades-gestión-innovación

\begin{tabular}{|c|c|}
\hline Capacidad de innovación & Medida de gestión \\
\hline $\begin{array}{l}\text { Estrategia } \\
\text { La empresa posee una estrategia clara y precisa, con ob- } \\
\text { jetivos y planes definidos, en los que identifica y apro- } \\
\text { vecha sus fortalezas específicas (calidad del producto, mar- } \\
\text { ca, flexibilidad en la gestión y rapidez en la respuesta a la } \\
\text { demanda), a fin de descubrir nuevas oportunidades, di- } \\
\text { versificar el negocio y optimizar los recursos tecnológi- } \\
\text { cos disponibles. }\end{array}$ & $\begin{array}{l}\text { El líder crea ambientes competitivos por } \\
\text { medio de la articulación de la visión de la } \\
\text { empresa con los objetivos previamente esta- } \\
\text { blecidos. }\end{array}$ \\
\hline $\begin{array}{l}\text { Cultura innovadora } \\
\text { Fomentar la interacción entre individuos es esencial en } \\
\text { el proceso de innovación, especialmente para la creación } \\
\text { de nuevas ideas, permitiendo la participación de los equi- } \\
\text { pos y optimizando nuevos modos de producción y de } \\
\text { administración. }\end{array}$ & $\begin{array}{l}\text { En la relación con los empleados en la em- } \\
\text { presa se comparten valores arraigados: trato } \\
\text { justo y equitativo, libertad, informalidad, } \\
\text { confianza, responsabilidad, trabajo en equi- } \\
\text { po, alto rendimiento, diversión, escogencia } \\
\text { de la gente adecuada, y como resultado se } \\
\text { tendrá la generación de un ambiente agrada- } \\
\text { ble, que incentiva la creatividad y el talento. }\end{array}$ \\
\hline $\begin{array}{l}\text { Condiciones del entorno } \\
\text { La empresa tiene un amplio conocimiento de las condi- } \\
\text { ciones de la industria y de su entorno, es decir además de } \\
\text { mantener vínculos y redes con proveedores, sectores in- } \\
\text { dustriales complementarios y centros de investigación tie- } \\
\text { ne una opinión clara y fundamentada sobre el impacto de } \\
\text { las políticas públicas en su sector. }\end{array}$ & $\begin{array}{l}\text { La empresa busca incrementar las oportuni- } \\
\text { dades de negocio por medio de nuevos so- } \\
\text { cios, proveedores y clientes. }\end{array}$ \\
\hline $\begin{array}{l}\text { Inteligencia competitiva } \\
\text { Reconoce los pasos que en el pasado le permitieron dar } \\
\text { saltos en la competitividad e identifica los cambios que } \\
\text { son necesarios en la actualidad, por razón de la evolu- } \\
\text { ción de la demanda y sus tendencias. }\end{array}$ & $\begin{array}{l}\text { Posee actividades proactivas, es decir, toma } \\
\text { medidas anticipándose a los cambios del en- } \\
\text { torno provocando transformaciones, con el } \\
\text { fin de triunfar ante el cambio, la compleji- } \\
\text { dad y el caos. }\end{array}$ \\
\hline
\end{tabular}




\begin{tabular}{|c|c|}
\hline Capacidad de innovación & Medida de gestión \\
\hline $\begin{array}{l}\text { Financiación de la innovación } \\
\text { Realiza anualmente una cantidad importante de inver- } \\
\text { siones en recursos e innovación. }\end{array}$ & $\begin{array}{l}\text { - Busca mejorar la liquidez y favorecer la con- } \\
\text { secución de los proyectos. } \\
\text {-Tener una mejor capacidad de respuesta frente } \\
\text { a posibles contingencias. } \\
\text {-Aumentar la estabilidad. }\end{array}$ \\
\hline $\begin{array}{l}\text { Ejecución de la innovación } \\
\text { La empresa realiza, sus prácticas con un alto nivel de } \\
\text { sistematicidad, con una alta evaluación en "articulación } \\
\text { y redes" y "aprendizaje y competencias", esto es facilita- } \\
\text { do porque cuenta con personal dedicado a las actividades } \\
\text { de innovación. }\end{array}$ & $\begin{array}{l}\text { Capacita a las personas de manera integral, } \\
\text { teniendo en cuenta además del desarrollo de } \\
\text { conocimientos y habilidades, los valores emo- } \\
\text { cionales como la autoconfianza, autocontrol, } \\
\text { empatía, trabajo en equipo e influencia, entre } \\
\text { otros. }\end{array}$ \\
\hline $\begin{array}{l}\text { Protección } \\
\text { La protección y conservación de los productos, los pro- } \\
\text { cesos y las innovaciones, a fin de mejorar la posición } \\
\text { competitiva de la empresa, por medio de un conjunto de } \\
\text { derechos exclusivos que protegen la actividad innovadora. }\end{array}$ & $\begin{array}{l}\text {-Protección de las innovaciones frente a los } \\
\text { competidores. } \\
\text {-Convertir las ideas en activos comerciales. } \\
\text {-Beneficiarse de la capacidad creativa e } \\
\text { innovadora de la organización. }\end{array}$ \\
\hline $\begin{array}{l}\text { Difusión y redes } \\
\text { Identifica claramente la importancia de la asociación para } \\
\text { la innovación, y participa activamente con otras entida- } \\
\text { des como universidades o consorcios tecnológicos. Por } \\
\text { lo tanto, posee alto conocimiento de los últimos avances } \\
\text { tecnológicos de la industria. }\end{array}$ & $\begin{array}{l}\text { Creación de alianzas que proporcionan acceso } \\
\text { a la información y a la formación. }\end{array}$ \\
\hline $\begin{array}{l}\text { Resultados } \\
\text { Durante los últimos años ha introducido nuevos produc- } \\
\text { tos y reconoce el impacto favorable que ello ha tenido en } \\
\text { términos de competitividad, rentabilidad y participación } \\
\text { en el mercado. }\end{array}$ & $\begin{array}{l}\text {-Rentabilizar los recursos invertidos. } \\
\text {-Definir las competencias exitosas } \\
\text {-Buscar el potencial de liderazgo }\end{array}$ \\
\hline
\end{tabular}

Fuente: elaboración propia con base en Asociación de la Industria Navarra (2008), De Saá (2006) Aguilar (2006), Bravo (2009), Senior (2006), CEPAL (2006) y Perozo (2005).

Según los componentes relacionados, las capacidades de gestión de innovación se definen como las habilidades para descubrir y cultivar talentos, por consiguiente se constituye la sabiduría colectiva en la empresa, materializada en mejoras significativas en procesos, bienes y servicios. Lo anterior puede llevarse a cabo realizando una adecuada formulación de estrategias y una óptima combinación de los recursos humanos, físicos $\mathrm{y}$ tecnológicos.

\section{Análisis de resultados}

El tejido empresarial del departamento de Boyacá es muy heterogéneo en cuanto a localización y composición. Las empresas del sector manufacturero estudiadas se encuentran concentradas en las ciudades de Duitama (40,2 \%), Sogamoso (25,9\%) y Paipa $(9,8 \%)$. La ciudad de Tunja, pese a ser la capital del departamento, no concentra actividades empresariales de manera significativa. 
En lo que se refiere a la composición de la población objeto de estudio, en su mayoría se trata de empresas con organización jurídica registradas como persona natural $(87.5 \%)$, también se evidencia que el rango de tiempo de permanencia en el mercado más frecuente no supera los veinte años, lo que indica las dificultades de las empresas para sostenerse y posicionarse en los mercados. Vale anotar que estos son reducidos y se limitan a atender el mercado local (62\%).

En el sector manufacturero de Boyacá, los subsectores más sobresalientes son agroindustria $(27,68 \%$ ) y metalmecánica $(19,64 \%)$. Por otro lado, en las empresas manufactureras predomina la presencia de microempresas. De acuerdo con el número de empleados, el $0,89 \%$ corresponde a grandes empresas, el $9,82 \%$ a medianas empresas y el $89,29 \%$ a microempresas. A continuación se analizan los resultados de la investigación, los cuales se presentan de acuerdo con las ocho variables establecidas para identificar la generación de capacidades de gestión de innovación en las empresas manufactureras, teniendo en cuenta que la identificación de capacidades científicas y tecnológicas es un componente fundamental en la definición de políticas públicas, y considerando a la innovación como fuente de competitividad (Vargas, 2004).

\subsection{Capacidades de vinculación}

Las relaciones externas de la empresa con otras empresas e instituciones, definen las capacidades de vinculación que le permiten afectuar transferencias de conocimientos y tecnologías para generar nuevas capacidades al interior de la empresa. De modo que esta exteriorización posibilita que la política de CTI contribuya a crear mecanismos que fortalezcan de manera sostenible la relación universidad-empresa-Estado y la integración de la infraestructura académica y productiva (Aguilar, 2005; Flores, 2005; Calderón, 2007; Robledo, 2008; Santos, 2008; Maldonado, 2004; Yoguel, 2000).

Las empresas del sector manufacturero de Boyacá presentan un bajo nivel de vinculación, lo cual puede tener explicación en la desconfianza e introversión de los empresarios. La Gráfica 1 muestra las instituciones con las que ha mantenido relación: las cámaras de comercio, el SENA, proveedores nacionales, las universidades y las instituciones gubernamentales. Esta relación se ha dado principalmente en la recepción de capacitaciones, asesorías y el cumplimiento de requisitos de normatividad (Gráfica 2).

Teniendo en cuenta que la empresa hace parte del Sistema Regional de Ciencia, Tecnología e Innovación, al igual que las entidades gubernamentales y académicas, se busca apreciar el nivel relacional de dichos agentes desde el punto de vista empresarial. 
A PUNTES DEL CEN ES №. 52

Vol. 30, Segundo Semestre de 2011

Gráfica 1. Entidades con las que se ha relacionado la empresa

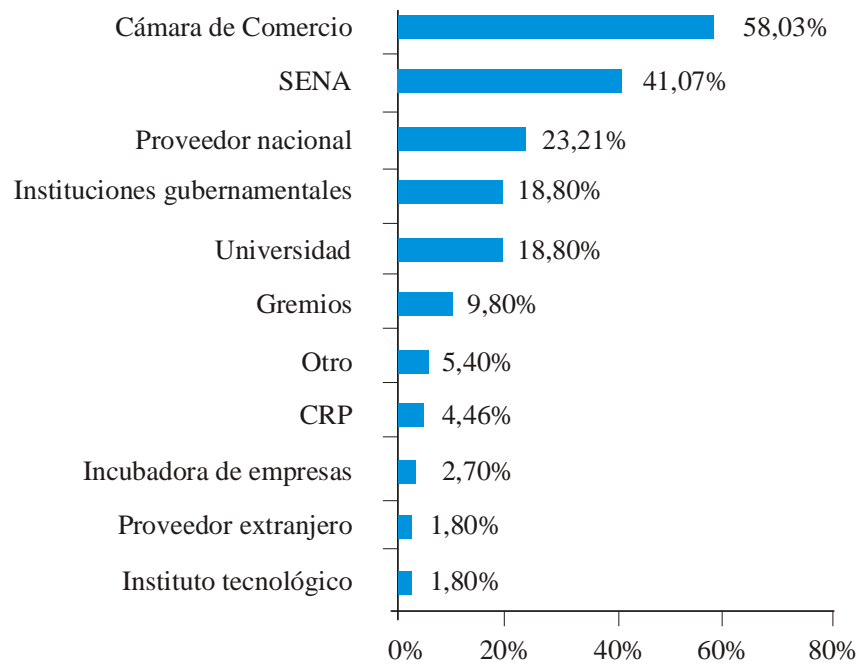

Fuente: (CREPIB, 2010)

Gráfica 2. Temas trabajados con estas entidades

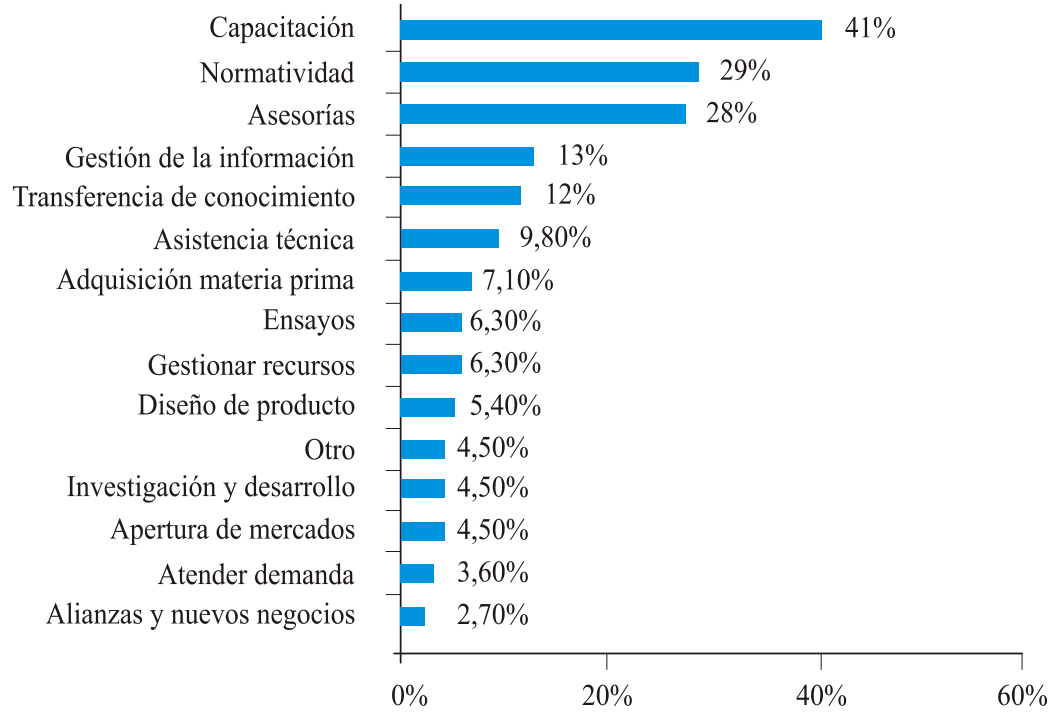

Fuente: (CREPIB, 2010) 
En este contexto se les pidió a los empresarios que calificaran su relación con las entidades externas por medio de los rangos: nulo, bajo, medio y alto. El $26.8 \%$ calificó a las cámaras de comercio en un grado intermedio, mientras que la relación con las demás entidades fue catalogada como nula.
Se ratifica la poca articulación de las empresas con los demás actores del Sistema de Ciencia, Tecnología e Innovación, partiendo del hecho que tan solo el $14 \%$ conoce las políticas de ciencia, tecnología e innovación por medio del internet y la invitación a participar en proyectos. (Gráfica 3).

Gráfica 3. Conocimiento de las políticas de ciencia, tecnología e innovación para fortalecer el sector empresarial
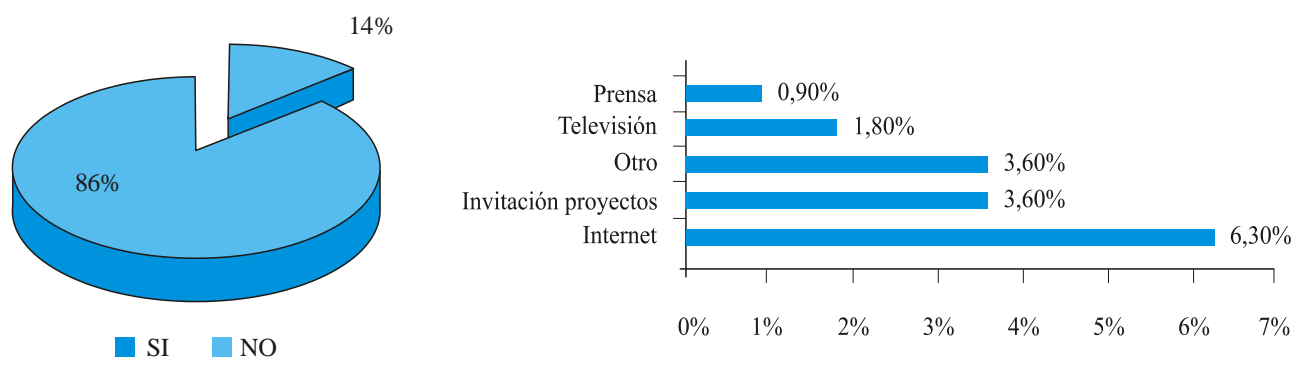

Fuente: (CREPIB, 2010)

La aplicación de las políticas de CTI ha sido poco efectiva, si se parte del poco conocimiento de su existencia por parte de las empresas, así como la reticencia de estas ante las entidades gubernamentales, teniendo en cuenta que la política posee mecanismos para establecer relaciones con otras entidades mediante programas de fomento empresarial y la formulación de proyectos de cofinanciación ${ }^{1}$.

\subsection{Comportamiento competitivo de la empresa}

En el análisis de las capacidades de gestión de la innovación de las empresas, es importante tener en cuenta el comportamiento competitivo, el mercado como eje transversal de las decisiones de la empresa, brinda las señales hacia donde debe dirigirse la actividad productiva (Santos, 2008;

\footnotetext{
Instrumento de la política de CTI, con el que el Estado apoya la financiación de programas estratégicos y proyectos de innovación y desarrollo tecnológico para que empresas colombianas presenten proyectos de desarrollo conjunto, con universidades, centros de investigación, centros de desarrollo tecnológico, Instituciones de formación tecnológica y otras instituciones con capacidades afines (COLCIENCIAS, 2010).
} 
Vargas, 2004; Asociación de la Industria Navarra, 2008). En este contexto, la política de CTI considera elemental financiar proyectos que contengan componentes de vigilancia tecnológica a los sectores productivos, que les permita identificar de manera sistemática oportunidades de modernización y transferencia de tecnología (Senior, 2006; Yoguel, 2000).

La diferenciación de la empresa frente a sus competidores es substancial en las motivaciones de innovación. Los factores que las empresas consideran como características diferenciales son la calidad en los productos (90\%), el servicio $(32 \%)$ y el precio $(30 \%)$; se resalta que la innovación (22\%) tiene menor importancia en las características diferenciales de las empresas.

En el desarrollo de estrategias en innovación y desarrollo tecnológico es necesario que se tengan conocimientos de mercados, esencialmente sobre los requerimientos de los clientes, basándose en que la producción debe estar focalizada en los clientes (Santos, 2008; Calderón, 2007). En consecuencia, los resultados de la encuesta permitieron identificar que el grupo de clientes, según el sector económico, se distribuye de la siguiente manera: Consumidor final
(91\%), consumidor empresarial (41\%) y entidades estatales (11\%).

Esta condición evidencia la reducida expansión de mercados del sector manufacturero de Boyacá, pues su campo de acción es en su mayoría local y regional. Adicionalmente, el $84 \%$ de los empresarios considera elemental la opinión de los clientes, pues de ellos depende fundamentalmente la aceptación de los productos en el mercado. La captura de esta opinión se realiza en el momento de la venta $(74 \%)$ y por medio de visitas continuas $(11 \%)$.

El marketing ha sido un tema al que se ha prestado poca atención, las estrategias no han tenido variaciones importantes en los últimos años, muestra de ello es que $\tan$ solo el $33 \%$ de las empresas ha hecho mejoras a los productos, acompañadas por modificaciones en sus estrategias de marketing.

Pese a esta condición, algunas empresas han desarrollado estrategias de manera informal, por medio del seguimiento de las tendencias del mercado, como se ilustra en la Gráfica 4. En consecuencia, la Gráfica 5, muestra que las estrategias más utilizadas son realizar servicio postventa $(24 \%)$ e intensificar la comunicación con los clientes (19.6\%). 
Gráfica 4. Origen de la estrategia de marketing

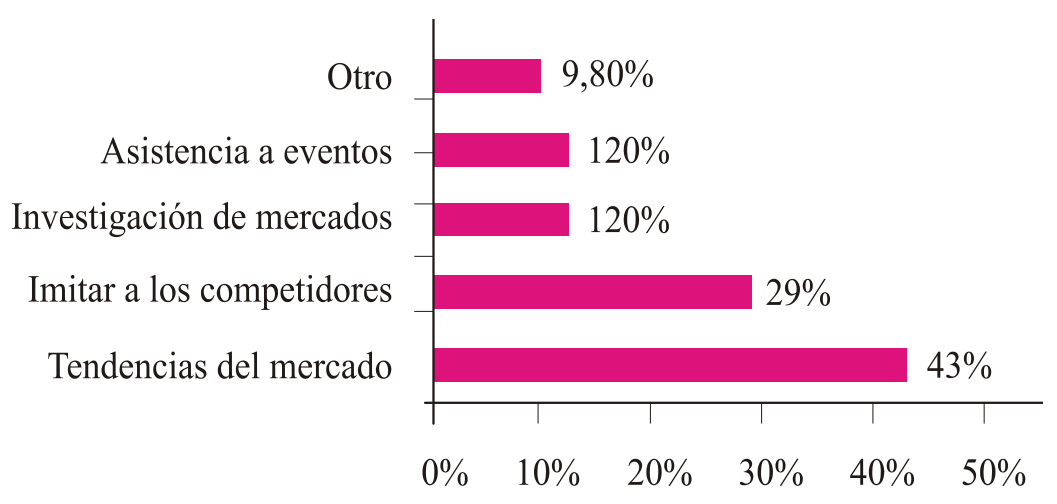

Fuente: (CREPIB, 2010)

Gráfica 5. Estrategias de marketing

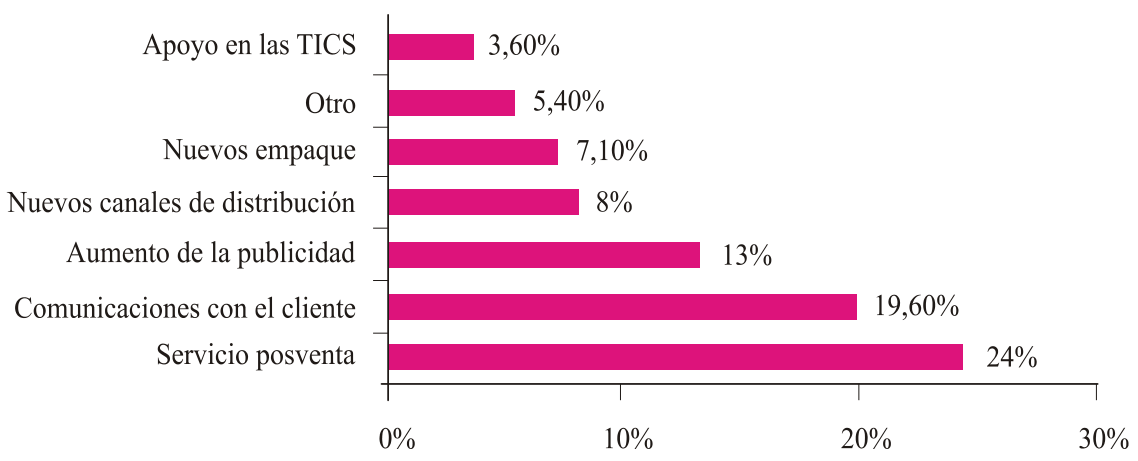

Fuente: (CREPIB, 2010)

Por otro lado, los empresarios de Boyacá consideran factores de calidad $(60 \%)$ y precios (62\%) como elementos relevantes en el momento de elegir sus proveedores. Cabe resaltar que la innovación (12\%) no es un aspecto significativo en la elección de los proveedores de las empresas del sector manufacturero de Boyacá.

\subsection{Innovación}

La innovación tecnológica se genera por medio de las estrategias formuladas 
formal o informalmente. Esta capacidad será evidenciada si las empresas destinan recursos y tiempo a actividades de investigación y desarrollo, por tanto se hace necesario que se diseñen, articulen y estimulen políticas e instrumentos para la inversión privada, doméstica o internacional, en ciencia, tecnología e innovación (Bravo, 2009; Malaver, 2004; Calderón, 2007)
(Objetivo No. 1 de la política de CTI, ver Tabla 3).

En esta variable se presentan las estrategias que están implementando las empresas, clasificadas en tres grupos: costos, productividad y marketing. Estas a su vez se encuentran ordenadas por prioridades, según el criterio de los empresarios (Tabla 6).

Tabla 6. Estrategias actuales de las empresas del sector manufacturero de Boyacá

\begin{tabular}{|l|c|l|c|l|c|}
\hline \multicolumn{2}{|c|}{ Costos } & \multicolumn{2}{c|}{ Productividad } & \multicolumn{2}{c|}{ Marketing } \\
\hline $\begin{array}{l}\text { Reducir } \\
\text { inventarios }\end{array}$ & $98 \%$ & $\begin{array}{l}\text { Mejorar calidad de } \\
\text { productos }\end{array}$ & $51 \%$ & $\begin{array}{l}\text { Conservar el } \\
\text { mercado actual }\end{array}$ & $38 \%$ \\
\hline $\begin{array}{l}\text { Emplear nuevos } \\
\text { materiales }\end{array}$ & $22 \%$ & $\begin{array}{l}\text { Aumentar } \\
\text { rentabilidad }\end{array}$ & $43 \%$ & $\begin{array}{l}\text { Abrir un nuevo } \\
\text { mercado }\end{array}$ & $37 \%$ \\
\hline $\begin{array}{l}\text { Adquirir } \\
\text { tecnología }\end{array}$ & $20 \%$ & $\begin{array}{l}\text { Aumentar volumen } \\
\text { producción }\end{array}$ & $28 \%$ & $\begin{array}{l}\text { Ampliar el } \\
\text { mercado actual }\end{array}$ & $36 \%$ \\
\hline $\begin{array}{l}\text { Reducir consumo } \\
\text { de energía }\end{array}$ & $19 \%$ & $\begin{array}{l}\text { Disminuir } \\
\text { devoluciones }\end{array}$ & $21 \%$ & Abrir líneas nuevas & $26 \%$ \\
\hline $\begin{array}{l}\text { Reducir costos } \\
\text { laborales }\end{array}$ & $17 \%$ & $\begin{array}{l}\text { Generar nuevos } \\
\text { procesos }\end{array}$ & $19 \%$ & $\begin{array}{l}\text { Productos ambien- } \\
\text { talmente limpios }\end{array}$ & $13 \%$ \\
\hline $\begin{array}{l}\text { Reducir costos } \\
\text { materias primas- } \\
\text { insumos }\end{array}$ & $17 \%$ & $\begin{array}{l}\text { Disminuir impacto } \\
\text { ambiental }\end{array}$ & $16 \%$ & $\begin{array}{l}\text { Reemplazar } \\
\text { productos } \\
\text { obsoletos }\end{array}$ & $13 \%$ \\
\hline $\begin{array}{l}\text { Reducir consumo } \\
\text { de agua }\end{array}$ & $12 \%$ & $\begin{array}{l}\text { Ampliar líneas } \\
\text { habituales }\end{array}$ & $12 \%$ \\
\hline
\end{tabular}

Fuente: (CREPIB, 2010)

En las estrategias de costos, la atención se enfoca en la reducción de inventarios y la utilización de nuevos materiales y tecnologías, los cuales brindan señales de una posible innovación en procesos (OCDE, 2005). Por otra parte, la capacidad productiva de una economía consiste en aumentar la disposición de los factores de producción (capital, tierra y trabajo) y una mayor eficiencia en los mismos (Villamil, 2003), constituyéndose la producción como la habilidad para transformar recursos que satisfagan los requerimientos del mercado (Robledo, 2009). 
En esta dirección, las empresas enfocan sus estrategias hacia el mejoramiento de la calidad, con la finalidad de aumentar sus niveles de producción y rentabilidad. Respecto a las estrategias de marketing, el $38 \%$ de las empresas prefiere mantenerse en el mercado, sin dejar de lado la posibilidad de ampliar los existentes y abrir nuevos mercados.

Si bien las empresas realizan esfuerzos en el cumplimiento de las estrategias, también se encuentran con factores que obstaculizan el logro de sus objetivos, entre los que se destacan el acceso al financiamiento (26\%), la falta de personal con características acordes a los requerimientos de la empresa (20,54\%), la competencia desleal $(17,5 \%)$ y las características del mercado $(4,5 \%)$. En lo concerniente al mercado, las empresas han buscado fortalecerse en este aspecto, principalmente en las motivaciones de inversión, en seguir las tendencias y aumentar las ventajas competitivas para mantenerse en el mercado, como se muestra en la Gráfica 6.

Gráfica 6. Motivaciones para la inversión en innovación
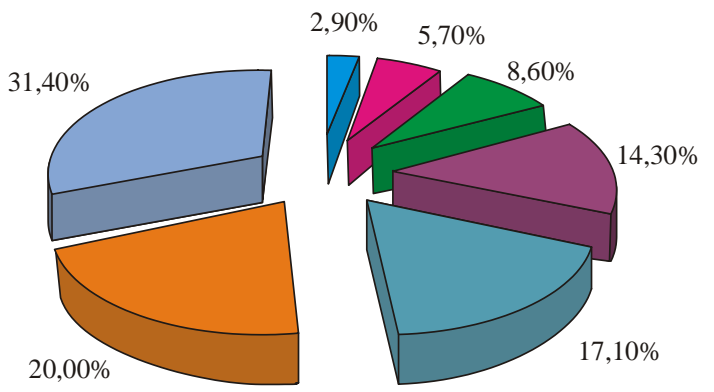

Cumplir la normatividad

Otro

Satisfacer la demanda

- Solucionar problemas actuales

Alcanzar sostenibilidad económica

Seguir tendencia del sector productivo

Aumentar la competitividad

Fuente: (CREPIB, 2010)

Sin embargo, se identifica que existen niveles bajos de inversión que no permiten que las empresas adopten nuevas tecnologías y generen innovaciones, para obtener una mejor posición competitiva ${ }^{2}$ (Najar, 2009). En el sector empresarial del departamento, la inversión en actividades I+D, ha sido baja, pues solo el $19 \%$ de las empresas encuestadas destina recursos para la generación de innovación, con aportes económicos $(28.6 \%)$ y de tiempo $(23.8 \%)$.

2 A nivel nacional, Boyacá ocupa el puesto número trece en cuanto a desarrollo en ciencia, tecnología y gestión empresarial, este comportamiento es similar en el escalafón de competitividad teniendo en cuenta el nivel bajo de diferenciación de la producción departamental respecto a empresas nacionales e internacionales. (Rozo, 2008). 
Es necesario que las empresas vinculen a la innovación en sus estrategias de modo que la consideren como un elemento potencial en el mejoramiento de sus actividades. Dentro de los instrumentos de política de CTI se encuentran programas como la recuperación del contingente ${ }^{3}$ para apoyo e incentivo a la inversión en actividades de investigaciones y desarrollo que llevan a la generación de innovación.

\subsection{Planificación en innovación y desarrollo tecnológico}

El proceso de planificación dentro de la empresa tiene en cuenta su proyección futura y el interés en desarrollar proyectos de innovación, por eso es necesario establecer estrategias con fines específicos. La planificación puede ser de carácter explícito (contenida en un plan estructurado) o implícito (informal). En el caso de las empresas del sector manufacturero del departamento de Boyacá, el $30.4 \%$ prefiere la planificación explícita, las demás prefieren hacer planificaciones temporales de acuerdo con la situación del mercado, de modo que las estrategias surgen de manera espontánea (CREPIB, 2010; CIDEM, 2002).

La Gráfica 7, muestra las proyecciones futuras de la empresa, percepción en la que los empresarios dan relevancia al mejoramiento de procesos, la ampliación de la capacidad instalada y la apertura de mercados a nivel nacional, así como también tienen presente la importancia del acceso a nuevas tecnologías y el desarrollo de nuevos productos para el mejoramiento de su empresa.

Si bien el deseo de incluir la innovación dentro de las proyecciones futuras aún es incipiente, los empresarios reconocen la importancia de generar innovación, más que todo en productos y procesos. Pese a esta apreciación, la tabla 7 permite deducir que no hay claridad en las actividades y conceptos, pues cuando se les pidió a los empresarios proponer actividades que promuevan la innovación en cada una de las áreas, su respuesta fue nula: marketing $(84,80 \%)$, procesos $(68,80 \%)$ y productos $(59,82 \%)$. Instrumento que busca apoyar con recursos financieros, la ejecución de proyectos de investigación que cumplan
ciertos criterios de calidad, pertinencia, eficiencia en el gasto, cuyos resultados sean relevantes y de impacto positivo a corto, medio y largo plazo en el sector beneficiario. 
Gráfica 7. Proyección de la empresa en dos años por porcentaje de empresas

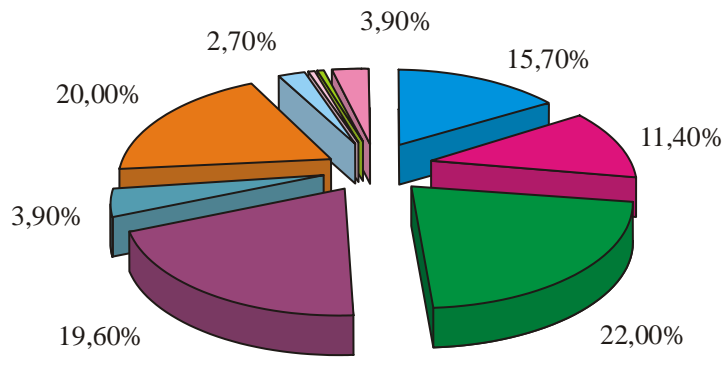

Desarrollar nuevos productos

Desarrollar tecnologías

Mejorar procesos

Abrir mercados nacionales

Abrir mercados internacionales

Ampliar capacidad instalada

Estandarizar procesos

Realizar fusiones

Adquirir franquicias

Otro

Fuente: (CREPIB, 2010)

Dentro de los intereses de los empresarios se resalta la innovación en productos, por medio del mejoramiento de las características del producto $(7,20 \%)$, principalmente el diseño $(9 \%)$. En segundo lugar se encuentra la innovación en procesos, se consideran necesarios el mejoramiento tecnológico $(11,7 \%)$ y la utilización de nuevas metodologías en procesos de calidad $(4,5 \%)$.
En lo referente a marketing, hay que anotar que es un área a la que poco se presta atención, lo cual puede ser explicado por el tamaño del mercado y la predisposición al cambio de los empresarios en la manera de vender sus productos. Las innovaciones en marketing pueden promoverse con ajustes en los precios (3,6\%) y empaques $(2,7 \%)$.

Tabla 7. Actividades propuestas para realizar innovaciones

\begin{tabular}{|l|c|l|l|l|l|}
\hline Innovación en productos & \multicolumn{2}{|c|}{ Innovación en marketing } & \multicolumn{2}{l|}{ Innovación en procesos } \\
\hline Sin información & $59,82 \%$ & Sin información & $84,80 \%$ & Sin información & $68,80 \%$ \\
\hline Diseño & $9 \%$ & Precios & $3,60 \%$ & Tecnología & $11,70 \%$ \\
\hline $\begin{array}{l}\text { Características del } \\
\text { producto }\end{array}$ & $7,20 \%$ & Empaques & $2,70 \%$ & Calidad & $4,50 \%$ \\
\hline Materias primas & $5,40 \%$ & Publicidad & $2,70 \%$ & Métodos & $4,50 \%$ \\
\hline Tecnología & $4,50 \%$ & Mercados & $1,80 \%$ & Materias primas & $3,60 \%$ \\
\hline Calidad & $3,60 \%$ & Aprovechamiento del internet & $0,90 \%$ & Capacitación & $3,60 \%$ \\
\hline Capacitación & $2,70 \%$ & Cumplimiento & $0,90 \%$ & Investigación & $1,80 \%$ \\
\hline Mercado & $2,70 \%$ & Aumentar comercialización & $0,90 \%$ & Mercado & $1,80 \%$ \\
\hline Investigación & $1,80 \%$ & Reducción de comercialización & $0,90 \%$ & & \\
\hline
\end{tabular}

Fuente: (CREPIB, 2010) 
Adicionalmente se demostró que el $75 \%$ de los empresarios estarían dispuestos a desarrollar proyectos de innovación a largo plazo. Estas iniciativas provienen principalmente de los propietarios $(58,3 \%)$ y clientes $(15,5 \%)$, dejándose al descubierto la baja influencia de los trabajadores en la generación de ideas, posiblemente por el bajo nivel educativo del recurso humano (Vargas, 2004).

Respecto a la formulación de estrategias que facilitan la competitividad (Asociación de la Industria Navarra, 2008), se observa que las empresas del departamento, en su mayoría, funcionan de manera rudimentaria, sin fundamentos sólidos de planificación lo que impide su crecimiento y proyección hacia otros mercados. En la región existen entidades de apoyo al sector empresarial en la formulación y ejecución de proyectos, pero es indispensable el interés y la disposición por parte de los empresarios (ver Tabla 3).

\subsection{Cultura de innovación}

En el desarrollo de los procesos de innovación, es necesario que se generen espacios favorables que permitan la cooperación entre los integrantes de la empresa y propicien un ambiente que de paso a la creatividad y la generación de ideas por medio de un sistema de aprendizaje continuo. Razón por la cual la política tiene como prioridad una cultura basada en la generación, la apropiación y la divulgación del conocimiento, la investigación científica, la innovación y el aprendizaje permanente (Bravo, 2009; Malaver, 2004).

Según Schumpeter (1935) no hay nadie más idóneo que el empresario para dirigir los procesos de innovación, pues es él quien detecta y pone en marcha las nuevas oportunidades de negocio, aprovechando ideas aún no explotadas (Calderón, 2007; Bravo, 2009). Por ello se estudió el liderazgo promovido por la gerencia en la promoción de la cultura de innovación, en las empresas de Boyacá, el cual es considerado en un grado intermedio $(46 \%)$.

En ese orden de ideas, se analiza también la labor de los empleados en la cultura de innovación, la cual requiere que estos no limiten sus capacidades a actividades meramente operacionales. En el sector manufacturero, según los empresarios encuestados, el $44.6 \%$ está interesado en contratar personal innovador, identificado en su mayoría por medio de pruebas y entrevistas que reflejen la creatividad de los aspirantes, que generen soluciones y mejoras a la empresa (Calderón, 2007).

Cabe resaltar que en la generación de nuevas ideas se considera como factor importante el otorgamiento de incentivos a los empleados. En Boyacá tan solo el $29.5 \%$ de las empresas cuenta con tales motivaciones (ver Gráfica 8), que en su mayoría son de carácter económico y de formación (Centro de Innovación y Desarrollo Empresarial [CIDEM], 2002). 


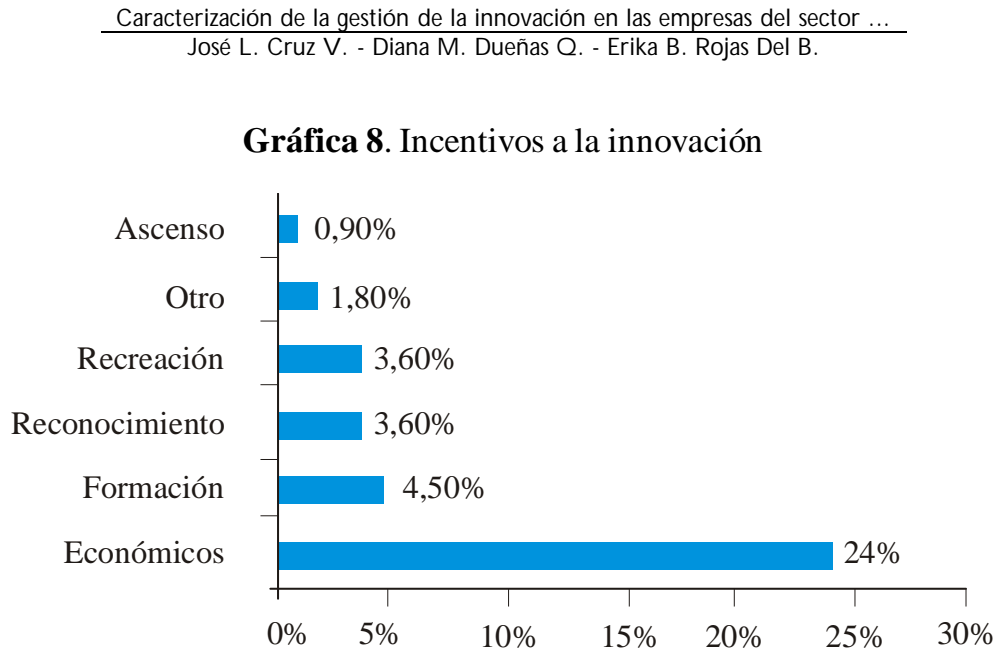

Fuente: (CREPIB, 2010)

Gráfica 9. Promoción del cambio

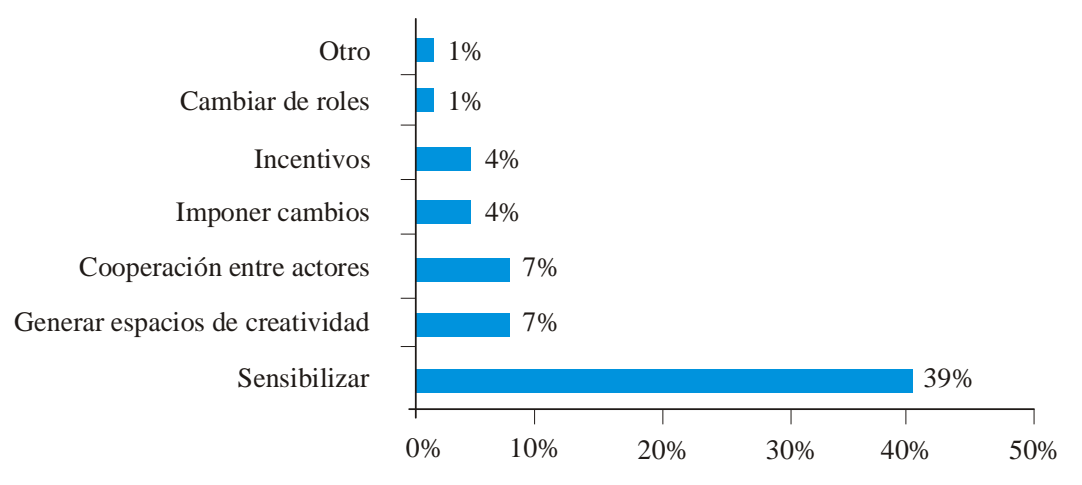

Fuente: (CREPIB, 2010)

Por otro lado, se destacan los cambios de transición dentro de la empresa, como resultado del intento de realizar procesos de innovación. Dichos cambios requieren acciones precisas por parte de la gerencia, dado que las transformaciones generadas pueden afectar la manera en que se ejecutan las actividades. En este caso, el $39 \%$ prefiere sensibilizar a sus empleados, así como propiciar espacios que inviten a la creatividad, como se ilustra en la Gráfica 9.

La cultura empresarial es un componente 
esencial en la competitividad, y se considera al liderazgo empresarial como la fuerza que impulsa el desarrollo. Por tanto se requieren líderes que no se limiten solamente a gerenciar recursos, sino que además estén interesados en generar conocimiento a partir de su capital humano, teniendo la convicción de que este último se ha convertido en el activo más importante, por poseer las capacidades, tal vez desconocidas, que deben ser despertadas por medio de estímulos y su vez originen vínculos estrechos entre este y la empresa (Varela, 2000).

\subsection{Talento humano}

Los recursos de una empresa pueden ser de dos tipos, tangibles e intangibles, los primeros se refieren a la planta, la maquinaria y las materias primas; es decir, que son físicamente palpables, mientras los intangibles son aquellos que no son palpables y difícilmente cuantificables, pero influyen en la competitividad (De Saá, 2006). sin duda, este elemento es relevante para la política de CTI, y está contenido en el objetivo No 3 (ver Tabla 3).

En el caso de los activos intangibles, la nueva economía del conocimiento considera que el capital intelectual especializado y altamente formado, actúa como un valor intangible de la empresa que hay que fidelizar, se puede decir que es un recurso elemental en la generación y consolidación de ventajas competitivas (Torrent, 2002; De Saá, 2006). Para el caso de Boyacá, el $55.4 \%$ de las empresas cuenta con empleados que estudian actualmente ya sea en la terminación del bachillerato o en carreras universitarias.

En este sentido, el aprendizaje es esencial en la incorporación de conocimiento, como resultado de actividades de investigación, búsqueda sistemática de la información y actividades informales, tales como capacitaciones (Malaver, 2004; Robledo, 2008). Precisamente para el caso de Boyacá las capacitaciones son iniciativa de la dirección de la empresa $(25 \%)$ y las entidades gubernamentales (14\%), siendo los empleados (1.8\%) los menos interesados en capacitarse en beneficio propio y de la empresa.

En efecto, los proveedores de las capacitaciones de orden institucional ratifican el actuar de la política de CTI en las empresas, por medio de la formación en temas que considera urgentes, en los que el Sena (24\%), las cámaras de comercio (15\%) y las entidades gubernamentales (11 $\%$ ) hacen parte de los programas regionales de ciencia y tecnología. Como se mencionó anteriormente, estas capacitaciones son efectuadas en torno a temas específicos relacionados con los requerimientos empresariales. Las temáticas más frecuentes son: seguridad industrial, para el caso del sector metalmecánico, y manipulación de alimentos en la agroindustria.

En referencia a la retención de personal, tan solo el $25 \%$ de las empresas toma acciones para retener el talento humano 
formado, con características potenciales específicas de la actividad económica en que se desenvuelve. Entre las acciones más frecuentes para retener el talento humano con mayores capacidades se encuentran: los incentivos económicos (16\%), los contratos $(4,5 \%)$ y los ascensos $(0.9 \%)$.

El capital humano ha sido un tema descuidado por parte de las empresas, pues se ejecutan capacitaciones por cumplir requisitos de normatividad, sin embargo existen programas de financiamiento de formación de recursos humanos por parte de la política de CTI, por medio de modalidades de créditos, pasantías, capacitaciones gerenciales en el exterior e intercambio de investigadores (COLCIENCIAS, 2010).

\subsection{Capacidad tecnológica}

En la búsqueda constante del éxito y la competitividad por parte de las empresas, la implementación de tecnologías se considera como instrumento de apoyo en las actividades productivas y como factor que otorga características diferenciales frente a otras empresas (Asociación de la Industria Navarra, 2008). En este contexto se requiere la implementación de programas que apoyen a las empresas en procesos de búsqueda, negociación, adquisición y transferencia de tecnología (Bravo, 2009; Malaver, 2004; Calderón, 2007). De acuerdo con lo anterior, se subraya que el $60 \%$ de las empresas utiliza herramientas automáticas en sus procesos productivos.

Adicionalmente, el $72.3 \%$ quiere incorporar nuevas tecnologías en búsqueda de organizar procesos $(29,5 \%)$ y diferenciarse de la competencia $(20.50 \%)$, como se nota en la Gráfica 10. En concordancia con las estrategias empresariales, se demuestra nuevamente el interés implícito de realizar innovación, ya que el mejoramiento de procesos prima sobre la reducción de costos.

Gráfica 10. Motivos de la adquisición de tecnología

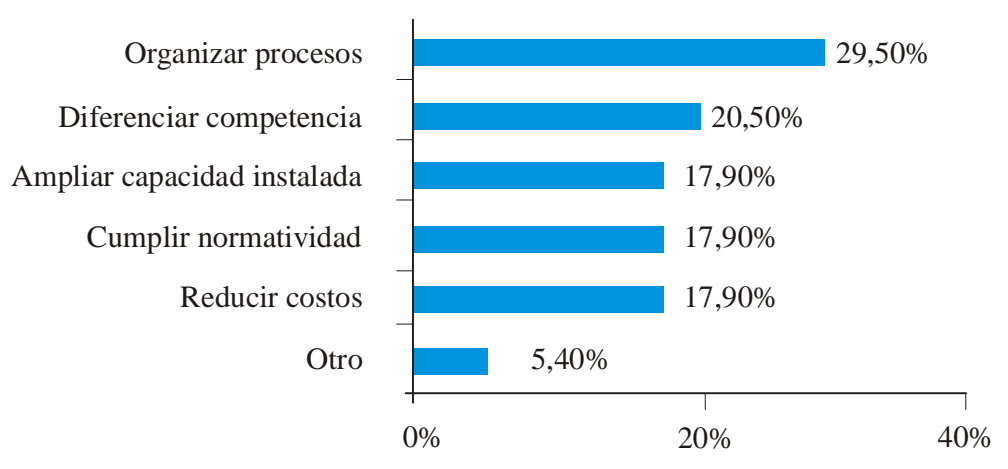

Fuente: (CREPIB, 2010) 
Gráfica 11. tipos de adquisiciones de tecnología
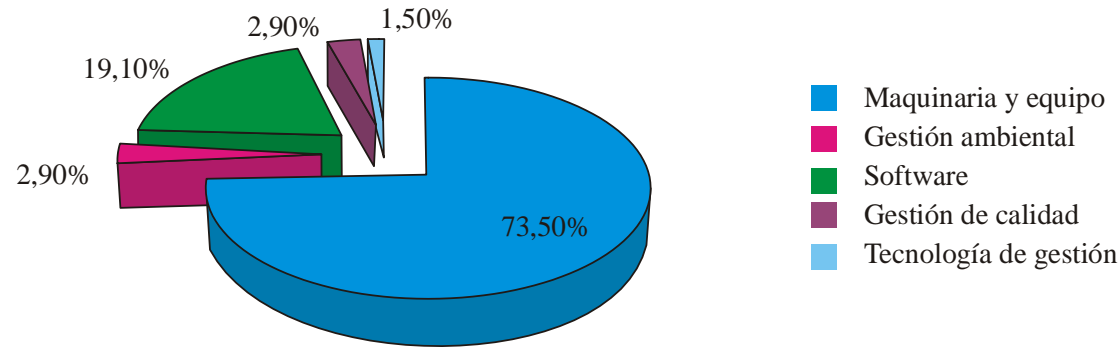

Fuente: (CREPIB, 2010)

Por consiguiente, analizando los tipos de adquisiciones de tecnología en los dos últimos años, el $45 \%$ ha adquirido tecnologías nuevas, especialmente de maquinaria y equipo (Gráfica 11). Siendo esta última la forma de adquisición prioritaria, con el fin de fortalecer el área de producción. También se identificó la compra de software contable, como herramienta de apoyo en procesos administrativos. La adquisición de estas tecnologías en su mayoría ha sido hecha por medio de la compra (58.04\%).

En el momento de la selección de tecnologías clave para el negocio, los empresarios tienen en cuenta la opinión de los proveedores de materias primas (23\%) y de expertos (17\%), teniendo como punto de referencia las tendencias del mercado en sus elecciones. Además, el $79 \%$ de las empresas cuentan con personal capacitado para el manejo de las tecnologías existentes, resaltando el desarrollo de capacidades ${ }^{4}$ como resultado del manejo rutinario de tecnologías.

En las empresas del sector manufacturero, el 79,5\% se encuentra en procesos de adaptación tecnológica; no obstante algunas microempresas han creado sus propias maquinas y por ende desarrollan las cuatro capacidades. Lo anterior permite afirmar que el recurso humano y su distribución al interior de la empresa son elementos esenciales en el desarrollo de capacidades.

El desarrollo tecnológico en el sector manufacturero de Boyacá ha sido pausado, lo cual puede tener explicación

\footnotetext{
$4 \quad$ Las capacidades desarrolladas comienzan con los procesos de adaptación de tecnología, se relacionan con el reconocimiento y manejo básico de la maquinaria. A manera de resultado del manejo constante, se crea una relación estrecha entre el trabajador y la herramienta, de modo que es capaz de realizar mantenimiento, más adelante podrá reconocer los daños que impiden el funcionamiento adecuado, en este punto puede realizar reparaciones y en un nivel más avanzado el operario es capaz de hacer algunas mejoras en la máquina, dependiendo de sus necesidades (Malaver, 2003).
} 
en que el sector industrial del departamento se ha caracterizado históricamente por presentar el fenómeno de desindustrialización ${ }^{5}$, colocándolo en desventaja a nivel nacional en la actualidad. (Rodríguez, 2005)

Contrariamente a esta situación las empresas no se han rendido en su intento por sostenerse y tratar de mejorar, aun con las condiciones de la economía nacional y particularmente con las importaciones que han bloqueado el campo de acción de las empresas. Como ejemplo se encuentra la imposibilidad de competir por precio debido a los costos de producción lo que acarrea consecuencias nefastas para la economía departamental, y el desempleo ${ }^{6}$ que se genera en las empresas que están a punto de cerrar. En otras palabras, las empresas se encuentran en una actitud de supervivencia, posiblemente producto de inversiones bajas en tecnologías.

\subsection{Gestión del conocimiento}

El Estado por medio de la política, de acuerdo con el objetivo No 4 (ver Tabla 3 ), pretende promover la formación del recurso humano para desarrollar las labores de ciencia, tecnología e innovación, en los procesos de innovación que resalta la gestión del conocimiento. Así que es trascendental observar el origen y la manera en que es procesado el conocimiento dentro de la empresa (Malaver, 2004; López, 2006; DANE EDIT II, 2009; Flores, 2005; Yoguel, 2000).

La capacidad de crear y aplicar conocimiento se constituye como una de las principales ventajas competitivas de las empresas (Asociación de la Industria Navarra, 2008). En el departamento de Boyacá, el conocimiento tácito $(52,70 \%)$ es la fuente de conocimiento más usual, trasmitido en un $80 \%$ durante la práctica de manera informal, debido a que existe un nivel bajo de documentación, pues es la manera rudimentaria de proteger el conocimiento; no obstante, el 5,4\% adelanta acciones formales para proteger el conocimiento generado dentro de la empresa.

En ese contexto, la aplicación del conocimiento a la actividad económica es una de las características principales de la nueva economía del conocimiento, que busca fundamentalmente reducir las fricciones, costos de transacción, negociación, búsqueda de información, toma de decisiones por medio de las tecnologías de la información y comunicación (TIC) (SAIZ, J.M., 2008; Pampillón, 2001; Torrent, 2002; De Saá, 2006).

Para el caso de Boyacá, el uso de tecnologías es aún bajo, tan solo el $16.1 \%$

\footnotetext{
Se refiere a la paulatina pérdida de la importancia de la industria fabril, teniendo en cuenta que la participación del departamento ocupa el puesto número diez para el 2009 con respecto al comportamiento de la industria de Boyacá a nivel nacional (Duran, 2009; Ramírez, 2009).

6 La política laboral se reforzó dando relevancia a la estabilidad laboral y partir del 2003 comenzó una recuperación lenta, en el 2007 se presenta una tasa de desempleo de $9.20 \%$ y en el 2008 de $7 \%$.
} 
de los empresarios considera como alto el uso de las TIC en sus actividades empresariales, lo cual puede tener explicación en la poca información y capacitación acerca de los beneficios de las TIC en la competitividad (Credé, 1998). El $46 \%$ de los empresarios utiliza el computador en actividades de la empresa como: contabilidad, procesador de texto y manejo de inventarios entre otros (Gráfica12).
Por otro lado, como se ilustra en la Gráfica 13 , el $25 \%$ utiliza internet como fuente de comunicación y el $57 \%$ de los empresarios encuestados no lo usa. El porcentaje restante manifiesta hacer buen uso de dicha herramienta, con el fin de acceder a la información, comunicarse con proveedores y clientes de manera rápida, de modo que se puedan tomar decisiones oportunas a menor costo y evitar asimetrías en la información (Pampillón, 2001).

Gráfica 12. Uso de computadores en la empresa

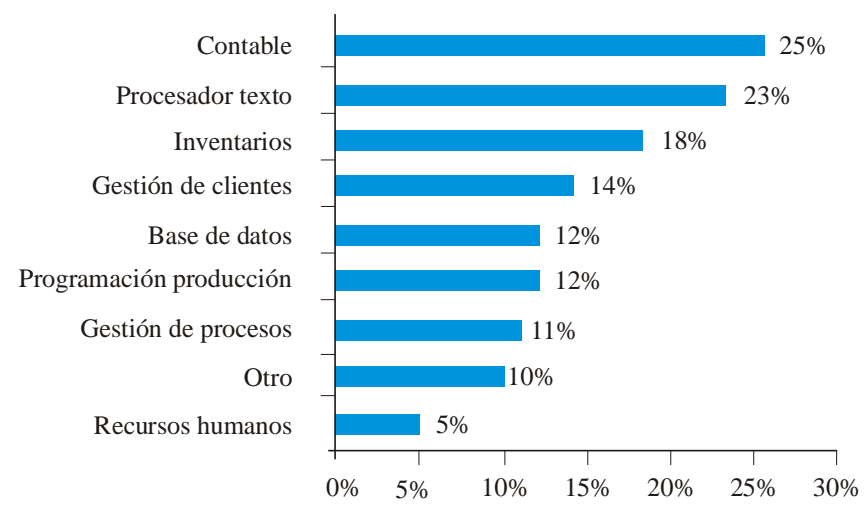

Fuente: (CREPIB, 2010)

Gráfica 13. Uso de internet dentro de las labores de la empresa

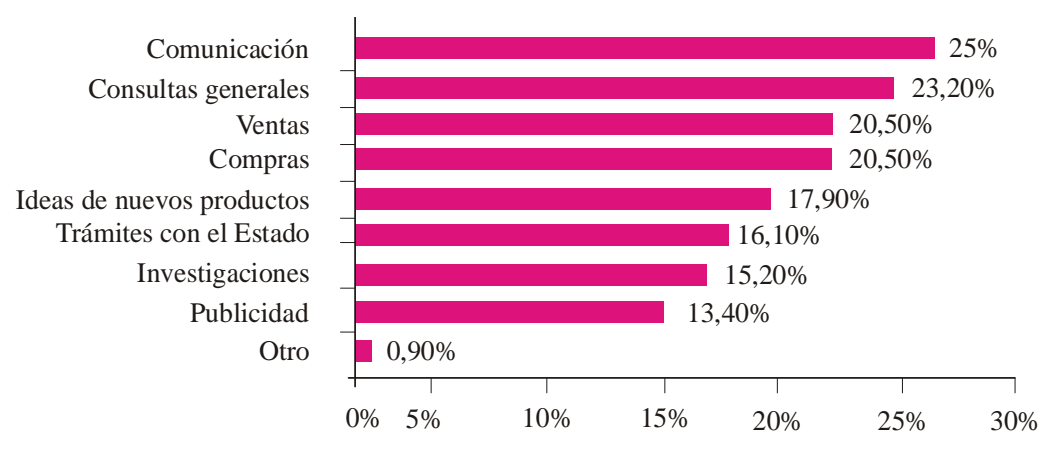

Fuente: (CREPIB, 2010) 
En este aspecto se resalta la existencia del instrumento TIC en PYMES, que busca emplear las tecnologías de la información y las comunicaciones (TIC), para generar innovaciones en producto, servicio o proceso, y mejorar la productividad y competitividad de PYMES que pertenezcan a cadenas productivas.

\section{Conclusiones}

- Las políticas de ciencia, tecnología e innovación en Colombia han sido desarrolladas de manera tardía, en comparación con el resto del mundo, pues se observa que estas tienen debilidad institucional y poco reconocimiento, por la baja difusión de los resultados de los proyectos con el sector productivo. En este sentido se nota que la articulación entre la academia y las empresas no ha sido suficiente para generar procesos de innovación radical y creciente, que procuren cambios socioeconómicos que impacten positivamente a la población.

- El sector empresarial del departamento de Boyacá ha sido influenciado por el comportamiento de la economía nacional,por el comportamiento del sector industrial y los cambios estructurales generados en los últimos veinte años en los ámbitos económico, político y social. Se aprecia la debilidad empresarial del departamento ante los ciclos económicos, en que las empresas internacionales e nacionales desplazan a las empresas boyacenses o ellas mismas salen del mercado por la poca resistencia ante las crisis.

- La cultura de innovación en Boyacá ha tenido un nacimiento lento y en pocas empresas. Generalmente la organización interna presta poca atención a la creatividad y al aporte de ideas de los empleados, brindan estímulos en materia de productividad, mas no en innovación. Esta situación parte primordialmente del individualismo del empresario, quien evita generar y compartir el conocimiento con otras personas, por el temor de que sus empleados puedan convertirse en su competencia.

- El capital humano ha sido un tema descuidado por parte de las empresas, pues se ejecutan capacitaciones por cumplir requisitos de normatividad, prueba de ello es que tanto la iniciativa como la oferta de capacitaciones provienen de entidades externas, mas no de la empresa, que debería proporcionar continuamente capacitaciones, que le permitan al personal ejercitar sus habilidades en beneficio de la empresa.

- Las fuentes de conocimiento de las empresas boyacenses son empíricas, principalmente por no poseer la orientación acerca de las nuevas formas de adquirir, procesar y transmitir conocimientos. Efectivamente hay que anotar que se requiere agilidad y eficiencia en los procesos. 
- Las capacidades de gestión de innovación de las empresas del sector manufacturero del departamento de Boyacá se encuentran en un nivel inicial, se evidencian falencias en cada una de las variables estudiadas, de modo que la participación de la política de CTI aún es preliminar, teniendo en cuenta que los programas regionales son desconocidos por parte de las empresas.
- El análisis de las políticas de CTI en la generación de capacidades de gestión de la innovación, se considera un aporte importante a los actores del Sistema Regional de Ciencia, Tecnología e Innovación, para fijar planes y programas que estimulen la apropiación social de conocimiento en innovación y desarrollo tecnológico, y permeen la cultura empresarial del sector manufacturero.

\section{R eferencias bibliográficas}

1. Abeledo, C. (2008). Análisis del desempeño de las funciones de un sistema nacional de innovación como marco para formular políticas.Ponencia presentada en el XII Seminario Altec 2007,Buenos Aires.

2. Aguilar, J. (Enero-junio de 2005). Modelos de acción organizacionales en la construcción de capacidades empresariales. Cuadernos de administracion, 18 (29), 16.

3. Aguilar, J. (2006). Gestión de capacidades dinámicas e innovación: una aproximación conceptual. Revista De Ciências Da Administraçao. Vol.8, $\mathrm{N}^{\circ}$. 16. pp. 280 - 292.

4. Albornoz, M. (2009). Desarrollo y políticas públicas en ciencia y tecnología en América Latina. RIPS. Revista de investigaciones políticas y sociológicas, $8(1), 12$.

5. Amézquita, C. (2008). La industria manufacturera en Colombia 1995-2005. Revista Facultad De Ciencias Económicas: Investigación y Reflexión. Vol 16, No. 2. pp. $61-78$.
6. Asociación de la Industria Navarra. (2008). Guía práctica. La gestión de la innovación en 8 pasos. Navarra, España: Asociación de la Industria Navarra. Recuperado de http:// www.navarrainnova.com/pdf/2008/ 8pasos.pdf.

7. Banco de la República. (2005, Diciembre). Notas económicas regionales. Región centro oriente. Recuperado de http:// www.banrep.gov.co/documentos/ publicaciones/pdf/ner-cent-orient-sep05.pdf.

8. Bravo, E. (2009). Capacidad de innovación y configuración de recursos organizativos. Intangible Capital , 20.

9. Calderón, G. (Julio-diciembre de 2007). Perfil cultural de las empresas innovadoras. Un estudio de casos en las empresas metalmecanicas. Cuadernos de Administracion 20 (34), 30.

10. Campos, G. (2008). El desarrollo de la ciencia y la tecnología en el ámbito regional. 
Revista electrónica de ciencias sociales, 22 (3).

11. Canales, A. (2007). La política científica y tecnológica en México: el impulso contingente en el periodo 1982-2006. Mexico: Instituto de Investigaciones sobre la Universidad y la Educación/Miguel Ángel Porrúa/SES.

12. Castellanos, C. (2004). Agenda prospectiva regional de ciencia y tecnología para el departamento de Boyacá. Tunja: Jotamar ltda.

13. Castellanos, C. (2007). Industrialización versus desarrollo regional. Tunja: Jotamar ltda.

14. Cely, S. L. (2006, Octubre). Manual de comision regional de competitividad de Boyaca. Recuperado de https:// www.mincomercio.gov.co/info/tlc/media/ file23261

15. Centro de Innovación y Desarrollo Empresarial CIDEM. (2002). Guía para gestionar la innovación. Barcelona: ACV Edicions. Recuperadode www.minetur.gob. es/Publicaciones/Publicacionesperiodicas/ .../150.p.

16. CEPAL. (2008, Octubre). Espacios iberoamericanos: la economía del conocimiento. Recuperado de http://www.eclac.cl/cgi-bin/ getProd.asp?xml=/publicaciones/xml/9/ 34459/P34459.xml\&xsl=/ddpe/tpl/p9f.xsl.

17. Chudnovsky, D. (1998). La política tecnológica y las PyMEs: fundamentos, objetivos y desafíos. Ciudad: Editorial.

18. COLCIENCIAS. (2005, Diciembre). Política de ciencia, tecnología e innovación hacia las regiones. Recuperado de http:// www.planeacion.uniminuto.edu/.../40- colciencias-politica-de-ciencia-tecno.

19. COLCIENCIAS. (2009, Abril). Programa de formación de alto nivel en gestión estratégica de la innovación. Recuperado de http://m.uninorte.edu.co/extensiones/cec/ secciones.asp?id=17.

20. Congreso de Colombia. (2009, $23 \mathrm{de}$ Enero). Ley 1286 de 2009. Recuperado de http://www.secretariasenado.gov.co/senado/ basedoc/ley/2009/ley_1286_2009.html

21. Credé, A. (1998). Las sociedades del conocimiento... en síntesis: la tecnología de la información para un desarrollo sustentable. Canada: Centro internacional de investigaciones para el desarrollo.

22. CREPIB. (2009). Encuesta cadena de valor en las empresas del sector agroindustrial. Tunja: Centro regional de gestion para la productividad y la innovacion de Boyacá.

23. CREPIB. (2005). Medianas y pequeñas empresas en el sector manufacturero de Boyacá. Tunja: Jotamar ltda.

24. CREPIB. (2010). Encuesta apropiación de la gestión del conocimiento, el desarrollo tecnológico y la innovación de las empresas del sector manufacturero de Boyacá. Tunja: Jotamar ltda

25. DANE. (2008). Formularios electronicos: Encuesta de desarrollo e innovación tecnológica EDIT I, II y III. Recuperado de http://www.dane.gov.co/index.php ?option $=$ com_content $\&$ view $=$ article $\&$ id=104\&Itemid=61.

26. De Saá, P. (2006). El conocimiento organizativo tecnológico y la capacidad de innovación. Evidencia para la empresa industrial española. Cuadernos de economía y dirección de la empresa (27), 28. 
27. Departamento Nacional de Planeación DNP. (1999). Plan nacional de desarrollo 19982002: cambio para construir la paz. Recuperado de http://www.lib.utexas.edu/ benson/lagovdocs/colombia/federal/ planeacion/PND-1998-2002.pdf.

28. Departamento Nacional de Planeación DNP. (2000, Junio). Conpes 3080. Política nacional de ciencia y tecnología 2000-2002. Recuperado de http://www.oei.es/salactsi/ Conpes.pdf.

29. Departamento Nacional de Planeación. (2003). Plan nacional de desarrollo: hacia un Estado comunitario 2002 -2006. Recuperado de http://www.dnp.gov.co/ Portals/0/archivos/documentos/GCRP/ PND/PND.pdf.

30. Departamento Nacional de Planeación. Dirección de Desarrollo Empresarial. (2006). Fundamentar el crecimiento y el desarrollo social en la ciencia la tecnología y la innovación. Bogotá: DNP. Recuperado de http://www.dnp.gov.co/Portals/0/ archivos/documentos/2019/Documentos/ documento_ciencia_tecnologia.pdf.

31. Departamento Nacional de Planeación. (2007). Plan nacional de desarrollo: Estado comunitario: desarrollo para todos 2006 2010. Recuperado de http://www.dnp.gov. co/PND/PND20062010.aspx.

32. Departamento Nacional de Planeación DNP. (2009, Abril). Conpes 3582. Recuperado de http://www.dnp.gov.co/Portals/0/archivos/ documentos/Subdireccion/Conpes/ 3582.pdf.

33. Duran, J. (2009). Aprendizaje productivo en la industria manufacturera de colombia. Un estudio a nivel de sectores. Cuadernos de economía, 29 (52).
34. Ekelund, R. (2003). Historia de la teoría económica y de su método. Madrid: McGraw-Hill Interamericana.

35. Flores, M. (2005). Gerencia del conocimiento: su relación con la generación de capacidades e innovaciones. Revista de ciencias sociales, XI (02), 18.

36. Garay, L. J. (2004). Colombia: estructura industrial e internacionalización 1967-1996. Bogota: Biblioteca Virtual del Banco de la República. Recuperado de http://www.ban repcultural.org/blaavirtual/economia/ industrilatina/indice.htm.

37. Gobernación de Boyacá. (2009, 19 de Octubre). Consejo Departamental de Ciencia Tecnología e Innovación CODECYT. Recuperado en http:// www.boyaca.gov.co/?idcategoria $=7439$.

38. Goméz, I. (2006). Gestión del conocimiento, innovación y competencia. Revista Escuela de Administración de Negocios EAM,(058), 29.

39. González, M. (2008). Políticas de innovación y servicios a empresas intensivos en conocimiento: una aproximacion general.Revista iberoamericana de ciencia, tecnología y sociedad, 4(10), 11.

40. Heijs, J. (2001). Justificación de la política de innovación desde un enfoque teórico metodológico. Documento de Trabajon ${ }^{\circ} 25$. Madrid: Instituto de Análisis Industrial y Financiero de la Universidad Complutense.

41. ITA. (2010, Mayo). Guía sobre gestión de la innovación. Recuperado de http:// plataforma.ita.es/file.php/1/guiaUsuario Flash/guia.html..

42. Kalmanovitz, S. (2003). Economía y nación 
una breve historia de Colombia. Bogota: Norma.

43. Londoño, J. E. (2004, Octubre). Plan de desarrollo departamental ¡Boyacá! deber de todos 2004 - 2007. Recuperado de www.planeacionboyaca.gov.co/.../plan/ plan_desarrollo.../departamen.

44. López, G. A. (Enero-junio de 2006). Perspectivas para el análisis de la innovación: un recorrido por la teoría. Cuadernos de Administración, 19 (31), 31.

45. Malaver, F. (Enero-junio de 2004). El comportamiento innovador en la industria colombiana: una exploracion de sus recientes cambios.Cuadernos de Administración, 17 (27), 29.

46. Malaver, F. (Julio-diciembre de 2004). Los procesos de innovación en la industria colombiana: resultado de un estudio de casos.Cuadernos de Administración, 17 (28), 34.

47. Malaver, F. (2003). La innovacion tecnológica en la industria colombiana. Bogotá: Pontificia Universidad Javeriana.

48. Maldonado, N. (2004). Innovación tecnológica como factor de aglomeración espacial en las regiones colombianas. Cuadernos de Economía, XXIII (41), 37.

49. Mayor, A. (1993). Las fábricas de hierro en Colombia en el siglo XIX. Revista Credencial Historia, No43, p. 8-13.

50. Najar, A. (2009). Productividad y competitividad del sector manufacturero de Boyacá 1990-2006. Tunja, Colombia: UPTC.

51. Ocampo, J. A. (1994). Historia económica de Colombia. Bogotá: Tercer Mundo.
52. Ocampo, J. A. (1984.). Crisis mundial, protección e industrialización.Bogotá: CEREC.

53. OCDE. (2005). Manual de Oslo. (3ra Ed.). Paris: OCDE.

54. Otero, J. (1984). Información para la planificación económica. Cuadernos de Ciencias Económicas y Empresariales regional. $\mathrm{N}^{\mathrm{o}} 13, \mathrm{p}$ 43-62.

55. Pampillón, R. (2001). La nueva economía: análisis, origen y consecuencias. Las amenazas y las oportunidades.Economía Industrial IV (340).

56. Pedroza, A. (2008). Gestión estratégica de la tecnología en el predesarrollo de nuevos productos.Journal of technology management \& innovation, 12.

57. Pérez, G. (2008). Los elementos de la Regionalización y la influencia de la planificación. Recuperado de: http:// www.oocities.org/es/acertijopilot/plan/ ii.foro2.plana.htm

58. Perozo, E. (2005). El impacto de la gestión tecnológica en el contexto empresarial. Revista venezolana de ciencias sociales Universidad Nacional Experimental Rafael María Baralt, 18.

59. Pindyck, R. (2009). Microeconomía. Madrid: Prentice-Hall.

60. Piñón, F. (2005). Ciencia y tecnología en América Latina: una posibilidad para el desarrollo. Revista Temas de Iberoamérica. Globalización, ciencia y tecnología. Vol 2, pp. $29-13$.

61. Ramírez, J. (2009). Escalafón de la competitividad de los departamentos en Colombia 2009. CEPAL Estudios y 
perspectivas (21).

62. Robledo, J. (Enero-junio de 2008). Estudio de un proceso de innovación utilizando la dinámica de sistemas.Cuadernos de Administración, 21 (35), 34.

63. Robledo, J. (2009). Encuestas, datos y descubrimiento de conocimiento sobre la innovación en Colombia. Bogotá: Pontificia Universidad Javeriana.

64. Rodríguez, E. (1987). La desindustrialización de Boyacá. Revista Apuntes del Cenes, UPTC, vol 6, Nº10. Pag. 97-11.

65. Rodríguez, E. (2005). Perfiles de la economía boyacense. Revista Apuntes del Cenes,UPTC, vol 1,No 48, p.95 - 124.

66. Rozo, J. (2008). Plan departamental de desarrollo: para seguir creciendo 2008 2011. Tunja: Gobernación de Boyacá.

67. Sáenz, J. F. (2000). Evolucion del sistema ciaencia, tecnologia e industria en el mundo y en la UE.

68. Saiz, J. M y Garcia, M (2008). Externalización de servicios y alianzas estratégicas en la nueva economía del conocimiento. Economía industrial. $\mathrm{N}^{\circ} 370$ pp. 135-141.

69. Santos, M. L. (2008). Efectos de la gestión de calidad total en la transformación en la innovación tecnológica y administrativa. Cuadernos de economía y dirección de empresa, 34.

70. SENA. (2001). Política nacional para la productividad y competitividad. Bogota: Bibliotecavirtual. Recuperado de http:// www.banrepcultural.org/blaavirtual/ ciencias/sena/cursos-de capacitacion/ politicanal/indice.htm.
71. Senior, A. (2006). Una aproximación a la gestión de ciencia y tecnología en las pyme's.Multiciencias Universidad de Zulia (02), 9.

72. Stiglittz, J. (2000). La economía del sector público. Barcelona: Antoni Bosch.

73. Tapias, H. (2005). Capacidades tecnológicas elemento estratégico de la competitividad. Revista de la Facultad de Ingeniería de la Universidad de Antioquia, 24.

74. UNESCO. (2010). Sistemas nacionales de ciencia, tegnología e innovación en América Latina y el Caribe. Montevideo: O?cina Regional de Ciencia para América Latina y el Caribe.

75. Varela, R. (2000, Septiembre). La cultura empresarial como estrategia de desarrollo. Recuperado de http://dspace.icesi.edu.co/ dspace/bitstream/item/4067/1/la_cultura_ empresarial_como_estrategia_de_desarrollo. pdf.

76. Vargas, M. (Abril, 2004). Los avances en la medición del desarrollo tecnológico en la industria colombiana. Revista CTS, 1 (2).

77. Velasco, E. (2007, Mayo). Innovación desde el modelo lineal hasta los sistemas de innovación. Recuperado de http://dialnet. unirioja.es/servlet/fichero_articulo? codigo $=2499438$.

78. Villamil, J.A. (Marzo, 2003). Productividad y cambio tecnológico en la industria colombiana. Economía y Desarrollo, 2 (1).

79. Yoguel, G. (2000). Sistemas locales de innovación y el desarrollo de la capacidad innovativa de las firmas: las evidencias del cuasi distrito industrial de Rafaela.REDES Universidad Nacional de Quilmes, (15), 51. 